\title{
DISTRIBUCIÓN ESPACIO-TEMPORAL DE LA SISMICIDAD SENTIDA EN COSTA RICA (1976-2013) EN EL MARCO HISTÓRICO DEL 30 ANIVERSARIO (1982-2012) DE LA RED SISMOLÓGICA NACIONAL (RSN: UCR-ICE)
}

\author{
GEOGRAPHIC AND TEMPORAL DISTRIBUTION OF FELT SEISMICITY \\ IN COSTA RICA (1976-2013) IN THE HISTORICAL CONTEXT OF THE 30 \\ ANNIVERSARY (1982-2012) OF THE NATIONAL SEISMOLOGICAL NETWORK \\ (RSN: UCR-ICE)
}

\author{
Lepolt Linkimer ${ }^{1,2}$ \& Guillermo E. Alvarado, ${ }^{1,3}$ \\ ${ }^{1}$ Red Sismológica Nacional (RSN: UCR-ICE) \\ ${ }^{2}$ Sección de Sismología, Vulcanología y Exploración Geofísica, Escuela \\ Centroamericana de Geología, Universidad de Costa Rica. Apdo. 214-2060, \\ San Pedro, Costa Rica \\ ${ }^{3}$ Área de Amenaza y Auscultación Sísmica y Volcánica, Instituto Costarricense \\ de Electricidad (ICE). Apdo. 10032-1000, San José, Costa Rica \\ *Autor para contacto: lepolt.linkimer@ucr.ac.cr
}

(Recibido: 10/08/2014; aceptado: 17/09/2014)

\begin{abstract}
The National Seismological Network of Costa Rica (RSN) was created in 1982 through an agreement between the Central American School of Geology of the University of Costa Rica and the Costa Rican Institute of Electricity. In this paper, we present a short review of the RSN contributions in Seismology to the Journal of Geology of Central America (RGAC) that is expressed in 63 publications. We also analyze the geographic and temporal distribution of 3363 earthquakes reported by the RSN through media reports and RGAC publications during 1976-2013. During the analyzed period the annual average of felt earthquakes in Costa Rica was 90, five 5.0-5.9-magnitude earthquakes were felt on average every year, and one 6.0-6.9-magnitude earthquake were felt every two years. Five earthquakes had a magnitude greater than 7.0 including the 1991 Limón $\left(7.7 \mathrm{M}_{\mathrm{w}}\right)$ and 2012 Samara $\left(7.6 \mathrm{M}_{\mathrm{w}}\right)$ earthquakes. The majority of felt earthquakes $(83,7 \%)$ had depths of less than $30 \mathrm{~km}$. The seismogenic sources with the greatest energy release were the shallow processes related to the subduction of the Cocos Plate $(54.5 \%)$ and the North Panama Deformed Belt (38,7\%).

Keywords: Seismicity of Costa Rica, Costa Rican seismic sources, active faults, earthquakes.
\end{abstract}


RESUMEN: La Red Sismológica Nacional (RSN) fue creada en 1982 mediante un convenio entre la Escuela Centroamericana de Geología de la Universidad de Costa Rica y el Instituto Costarricense de Electricidad. En este artículo presentamos una breve reseña de los aportes de la RSN en la investigación sismológica que tan sólo en la Rev. Geol. Amér. Central (RGAC) se encuentra plasmada en 63 publicaciones. Además, analizamos la distribución espacio-temporal de 3363 sismos sentidos difundidos por la RSN a través de comunicados y publicaciones en la RGAC durante 1976-2013. Para el periodo analizado el promedio anual de sismos percibidos en Costa Rica fue de 90, se sintieron en promedio 5 sismos de magnitud 5,0-5,9 cada año y un sismo de magnitud de 6,0-6,9 cada dos años. Cinco terremotos sobrepasaron la magnitud de 7,0, siendo los más grandes el terremoto de Limón de $1991\left(\mathrm{M}_{\mathrm{w}}\right.$ 7,7) y Sámara del 2012 $\left(\mathrm{M}_{\mathrm{w}} 7,6\right)$. La mayoría de los sismos sentidos $(83,7 \%)$ tuvieron profundidades menores a $30 \mathrm{~km}$. Las fuentes sismogeneradoras con mayor liberación de energía fueron los procesos superficiales de la subducción de la placa del Coco $(54,5$ \%) y el Cinturón Deformado del Norte de Panamá (38,7 \%).

Palabras clave: Sismicidad de Costa Rica, fuentes sísmicas de Costa Rica, fallas activas, terremotos.

\section{INTRODUCCIÓN}

Los sismos sentidos son muy frecuentes en Costa Rica y su ocurrencia es motivo de gran interés, tanto de la comunidad científica como de la población en general. Tan solo en la Rev. Geol. Amér. Central (RGAC), a lo largo de los últimos 30 años, el estudio de los sismos está plasmado en 55 artículos y 29 notas técnicas, que tienen por énfasis el estudio de las causas y consecuencias de los sismos y la descripción general de la sismicidad del país. La mayor parte de estas investigaciones (63) están basadas en datos de la Red Sismológica Nacional (RSN:UCR-ICE), la cual es la instancia más antigua en Costa Rica de las existentes dedicadas a la vigilancia sísmica del país.

La alta sismicidad de Costa Rica se debe a su localización en una zona de subducción y cerca del punto triple entre las placas del Coco, Caribe y Nazca (Fig. 1). La sismicidad es especialmente abundante a lo largo de la Fosa Mesoamericana y en la zona sismogénica interplacas, donde se subduce la placa del Coco debajo de la placa Caribe y la microplaca de Panamá. Además, la sismicidad es abundante a lo largo de la Zona de Fractura de Panamá (ZFP), la cual sirve de límite entre las placas del Coco y Nazca. Adicionalmente, ocurren muchos sismos en el Cinturón Deformado del Norte de Panamá (CDNP) y el Cinturón Deformado del Centro de Costa Rica (CDCCR), los cuales son anchas zonas de deformación con una alta densidad de fallas activas, que se han postulado como los límites entre la placa Caribe y la microplaca de Panamá (Fig. 1). Desde 1821, año en que Costa Rica adquiere su independencia, el país ha sufrido 67 sismos destructivos, de los cuales 14 han tenido magnitudes mayores a 7,0.

Un sismo (o temblor) es el movimiento percibido o registrado en la superficie de la corteza terrestre como resultado de la ruptura súbita de las rocas y de la capacidad de las mismas para deformarse elásticamente con el paso de ondas elásticas. La mayoría de los sismos provienen de rupturas muy pequeñas en las rocas y estos son imperceptibles por la población. Las rupturas más grandes producen sismos que son percibidos y en ocasiones pueden causar serios daños en infraestructura, cambios en el paisaje y pérdida de vidas humanas. En Latinoamérica estos eventos se denominan terremotos.

En este artículo hacemos un recorrido por los sismos sentidos en Costa Rica durante el periodo 1976-2013 y que han sido reportados por la RSN en boletines mensuales de sismos sentidos que se publican desde julio de 1976 y en numerosas publicaciones en la RGAC. Enfocamos el análisis de la sismicidad en la distribución temporal, geográfica, por magnitud, profundidad y origen de los sismos más importantes. Asimismo, presentamos una breve reseña histórica de la RSN, los aportes de la RSN en la investigación de la Sismología que han sido divulgados en la RGAC y el proceso de difusión del reporte de sismos sentidos que se ha llevado a cabo en la RSN desde 1976. 


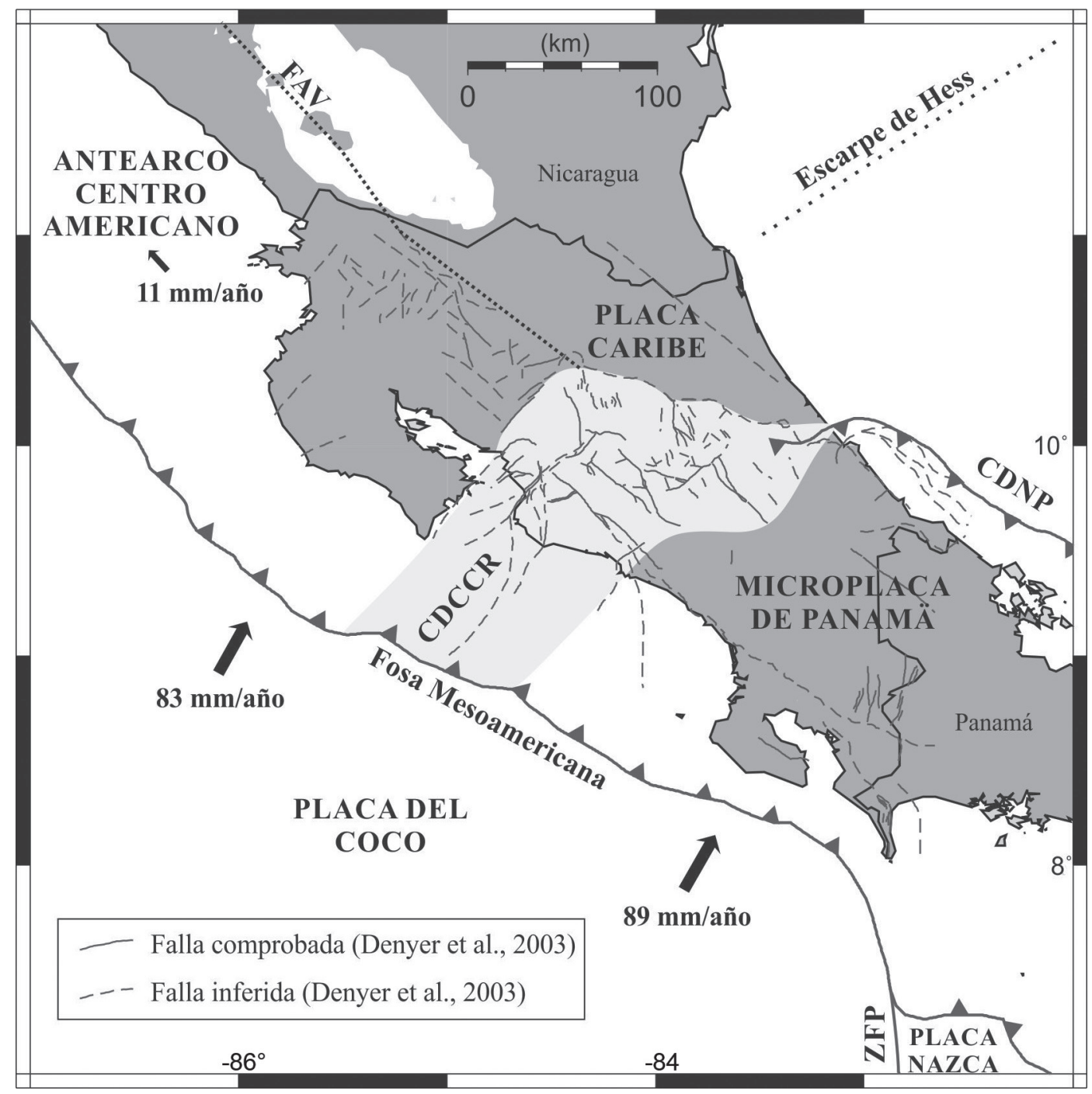

Fig. 1: Mapa tectónico simplificado de Costa Rica incluyendo fallas del Cuaternario de acuerdo con Denyer et al. (2003). La región de color gris claro denota el Cinturón Deformado del Centro de Costa Rica (CDCCR) de acuerdo con Montero \& Rojas (2014). La línea punteada representa el límite noreste simplificado del Bloque Antearco Centroamericano a lo largo de las Fallas del Arco Volcánico (FAV) de acuerdo con Franco et al. (2012). CDNP significa Cinturón Deformado del Norte de Panamá y ZFP Zona de Fractura de Panamá.

\section{BREVE RESEÑA HISTÓRICA DE LA RSN}

La RSN (UCR-ICE) es uno de los centros dedicados a la vigilancia sísmica de Costa Rica. La RSN fue creada mediante un convenio entre la Sección de Sismología, Vulcanología y Exploración Geofísica de la Escuela Centroamericana de Geología (ECG) de la Universidad de Costa Rica (UCR), que funciona desde 1973 y el Área de Amenazas y Auscultación Sísmica y Volcánica del Instituto Costarricense de Electricidad (ICE), que funciona desde 1974. Esta última entidad además incluye al Observatorio Sismológico y Vulcanológico del Arenal y Miravalles (OSIVAM), creado en 1994. El centro de registro conjunto de la RSN opera desde 1982 y tiene por sede la ECG de la UCR. 
La RSN surge como una red conjunta entre varias instituciones costarricenses con el fin de unificar esfuerzos y optimizar fondos e infraestructura. Los orígenes de la RSN se remontan a la actividad del volcán Irazú en 1963. Esta emergencia motivó la cooperación internacional por la que la Dirección de Geología, Minas y Petróleo obtuvo una donación del Servicio Geológico de los Estados Unidos que consistía en tres estaciones sismológicas, las cuales fueron instaladas en 1965 en La Lucha, el Sanatorio Durán y en San Pedro de Poás (Morales, 1986). Por otro lado, el ICE en conjunto con la UNESCO, creó en 1964 un búnker de protección para los vulcanólogos y para la instalación de equipos que vendría a consistir en el primer Observatorio Vulcanológico de América Central. En 1971, a través de las diligencias del Dr. César Dóndoli, director y fundador de la ECG, se transfiere el equipo sismológico desde la Dirección de Geología, Minas y Petróleo hacia la ECG. Además en 1970, la ECG abre los cursos de geofísica dando un impulso adicional al desarrollo de la Sismología en Costa Rica (Morales, 1986).

La erupción del volcán Arenal en 1968 y los terremotos de Managua en 1972 y Tilarán en 1973, impulsan aún más la investigación científica y aplicada alrededor de los sismos y volcanes en Costa Rica (Alvarado \& Morales, 1988). En 1973, la ECG, con el apoyo de la Organización de Estados Americanos (OEA), organiza una red de estaciones sismológicas alrededor del Valle Central (RSN, 1985; Morales, 1986). Por su parte en 1974 el ICE desarrolla los primeros estudios sismológicos en la región donde se planeaba construir el Complejo Hidroeléctrico Arenal-Corobicí, instalando la primera red sísmica telemétrica en América Central, llamada red de Arenal, con un centro de registro ubicado cerca de la ciudad de Tilarán (RSN, 1985). Esta red permitió caracterizar por primera vez localmente la sismicidad de la región, definir la fuente sísmica del terremoto de Tilarán en 1973, y además desarrollar el primer modelo de corteza para la región noroeste de Costa Rica (Matumoto et al., 1977). En julio de 1975, la ECG organiza con el apoyo de la OEA el primer seminario latinoamericano sobre riesgo sísmico y volcánico y la Sección de Sismología y Vulcanología de la ECG publica su primer boletín sismológico mensual (RSN, 1985). En julio de 1976, la ECG publica su primer boletín mensual con la información de los sismos sentidos en Costa Rica, el cual se mantiene hasta la fecha. Entre 1976 y 1982, tanto la ECG como el ICE continúan ampliando sus redes de estaciones sismológicas y creciendo en el campo de la localización de sismos. En 1982, se pone en marcha un programa de colaboración institucional para la observación sismológica del país en el cual participan el departamento de Geología del ICE, la Sección de Sismología y Vulcanología de la ECG y el programa de investigaciones vulcanológicas de la Escuela de Geografía de la Universidad Nacional (UNA). De esta forma, se crea así la llamada "Red Sismológica Nacional (RSN: ICEUNA-UCR)", con estaciones distribuidas de tal manera que permitieran la cobertura de la sismicidad del país, optimizar los fondos y el personal y generar una base de datos única. En julio de 1983, la UNA se retira del esfuerzo conjunto ante la aparición de un proyecto con la Universidad de California en Santa Cruz (Morales, 1985). Es así, como a partir de 1984 comienza a funcionar independientemente la red del OVSICORI en la UNA (Morales, 1985). Adicionalmente y bajo el amparo del proyecto de la Universidad de California en Santa Cruz, el Instituto de Investigaciones en Ingeniería de la UCR (INII) logra instalar una pequeña red de estaciones acelerógraficas también de forma independiente de la red de acelerógrafos que posee el ICE y de la red de sismógrafos que componen la RSN (Morales, 1985).

Actualmente, la red sísmica de la RSN está constituida por 62 estaciones permanentes ubicadas en diferentes partes del territorio costarricense (Fig. 2) y varias decenas más de estaciones temporales para estudios locales y especializados del ICE. La mayoría de estaciones de la red permanente son sismómetros de banda ancha de tres componentes, pero además existen estaciones con sismómetros de periodo corto. Las estaciones llegan al centro de registro de la UCR a través de diferentes rutas por vía de línea telefónica, internet y radio. Desde agosto del 2011, se implementaron 


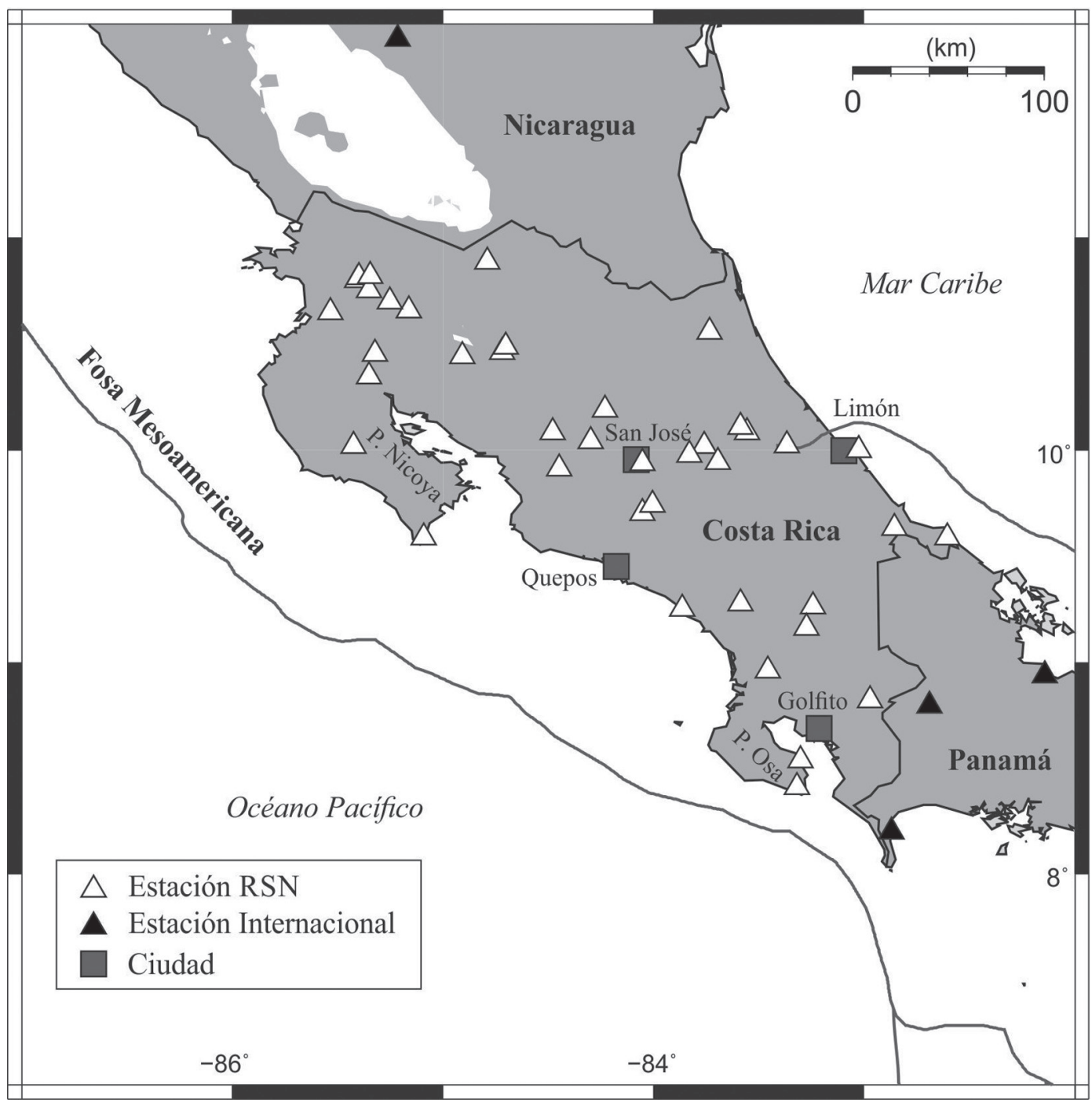

Fig. 2: Mapa de estaciones de la Red Sismológica Nacional durante el 2013. El mapa muestra estaciones internacionales de las que se reciben señales sísmicas en Nicaragua (INETER) y Panamá (Universidad de Panamá y Observatorio Sismológico del Occidente de Panamá).

los sistemas Seiscomp y Earthworm que constituyen el sistema automático de detección de sismos locales, regionales y globales. Unas 50 estaciones adicionales, administradas por el ICE, están ubicadas en sitios donde no existe la posibilidad sencilla de transmitir la información por medio electrónico. Entre estas estaciones se encuentran algunas de la red OSIVAM, las cuales se utilizan para monitorear la sismicidad y actividad volcánica alrededor de los volcanes Arenal, Miravalles,
Rincón de la Vieja y Tenorio. Muchas de estas estaciones, que están destinadas a estudios específicos de proyectos y obras hidroeléctricas y geotérmicas del ICE, no son usadas en la localización rutinaria de la RSN, pero son añadidas posteriormente a la base de datos con el fin de mejorar la localización de los sismos.

Cabe mencionar que en Costa Rica, la Comisión Nacional de Prevención de Riesgos y Atención de Emergencias (CNE), es 
la institución pública rectora en lo referente a la coordinación de las labores preventivas de situaciones de riesgo inminente, de mitigación y de respuesta a situaciones de emergencias que involucran actividad sísmica y volcánica. Dentro de la CNE, existe un organismo de coordinación denominado Comité Técnico Asesor (CAT) de Sismología y Vulcanología, en el que la RSN tiene una activa participación.

El trabajo conjunto de los investigadores del ICE y la UCR, como parte de la RSN, ha llevado a la acumulación de valiosa información, que incluye una base de datos de localizaciones de sismos que se extiende desde 1974 hasta el presente, así como la difusión de un reporte para cada sismo percibido por la población luego de su ocurrencia. También se ha contado con la colaboración de científicos e instituciones a nivel nacional e internacional para estudios específicos y capacitaciones. Paralelamente se han divulgado gran cantidad de estudios sismológicos, muchos de los cuales han sido publicados en la RGAC como se detalla en el siguiente apartado.

\section{APORTE DE LA RSN EN LA RGAC}

El aporte de la RSN a la investigación en temas relacionados con la Sismología ha sido notorio durante los últimos 30 años. Desde la primera publicación de la RGAC en 1984 y hasta el volumen 50 publicado en el año 2013, un total de 84 publicaciones (55 artículos y 29 notas técnicas) han sido dedicadas a temas de la Sismología. Esto representa el $17 \%$ del total de publicaciones que se han presentado en la RGAC a lo largo sus 30 años (Fig. 3A). Las publicaciones en Sismología representan igualmente el $17 \%$ del total de páginas publicadas. De las 84 publicaciones en esos tres decenios, los investigadores de la RSN, tanto del ICE como de la UCR, han estado involucrados como autores en 63 publicaciones, lo cual representa el $75 \%$ de los trabajos en el campo de la Sismología (Fig. 3B) y el 13\% de la totalidad de las publicaciones de la RGAC durante sus 50 volúmenes.

Los temas aportados por los investigadores de la RSN en estas 63 publicaciones de la RGAC tratan especialmente la sismicidad reciente e histórica de Costa Rica (por ejemplo: Morales \& Montero, 1984; RSN, 1985, 1986, 1987a, 1987b, 1988a, 1988b, 1989, 1990, 1991, 1992, 1994, 1995, 1996, 1998, 2001, 2002, 2009; Alvarado \& Morales, 1988; Rojas et. al., 1993; Boschini \& Montero, 1994; Fernández \& Barquero, 2004, 2005; Barquero et al., 2006, 2012; Peraldo \& Montero, 2007; Barquero \& Rojas, 2009, 2010 y Linkimer et al., 2013). En estos artículos se describe la sismicidad de Costa Rica durante períodos específicos y se presentan las localizaciones de los sismos más relevantes, así como datos de intensidades y efectos de estos sismos.

Otro grupo importante de publicaciones están dirigidas a detallar terremotos particulares como Osa en 1879 (Peraldo et al., 2006), Orotina en 1924 (Montero, 1999), Patillos en 1952 (Montero \& Alvarado, 1995), Buenavista de Pérez Zeledón en 1983 (Boschini et al., 1988; Mora \& Peraldo, 2011), Limón en 1991 (Montero et al., 1994a, 1994b; Ponce et al., 1994; Barquero \& Rojas, 1994 y Morales, 1994), Quepos en 1999 (Rojas \& Redondo, 2002), Cinchona en 2009 (RSN, 2009) y Sámara en 2012 (Linkimer et al., 2013). En estas publicaciones se detallan aspectos de la localización de los terremotos usando diferentes métodos, así como la localización de réplicas e información macrosísmica.

La sismotectónica y las zonas sísmicas de Costa Rica se han descrito en varios artículos como Morales (1985), Montero (1986), Montero \& Morales (1990) y Montero et al. (1994a). La sismotectónica y sismicidad de regiones más específicas ha sido incluida en un número importante de artículos, por ejemplo para la región central de Costa Rica (Fernández et al., 1996; Fernández 1996; Fernández \& Pacheco, 1998; Montero, 2001) y más específicamente para el extremo occidental de la cordillera volcánica central (Alvarado et al., 1988; Montero et al., 2010), la zona entre Cartago y San José (Fernández \& Montero, 2002; Montero et al., 2005), la zona de Turrialba-Irazú (Montero, 2003), los valles de Coris y El Guarco (Montero \& Kruse, 2006), la zona del volcán Poás (Montero et al., 2010), el volcán Irazú (Barquero et al., 1995; Fernández et al., 1998; Montero et al., 2013), la península 

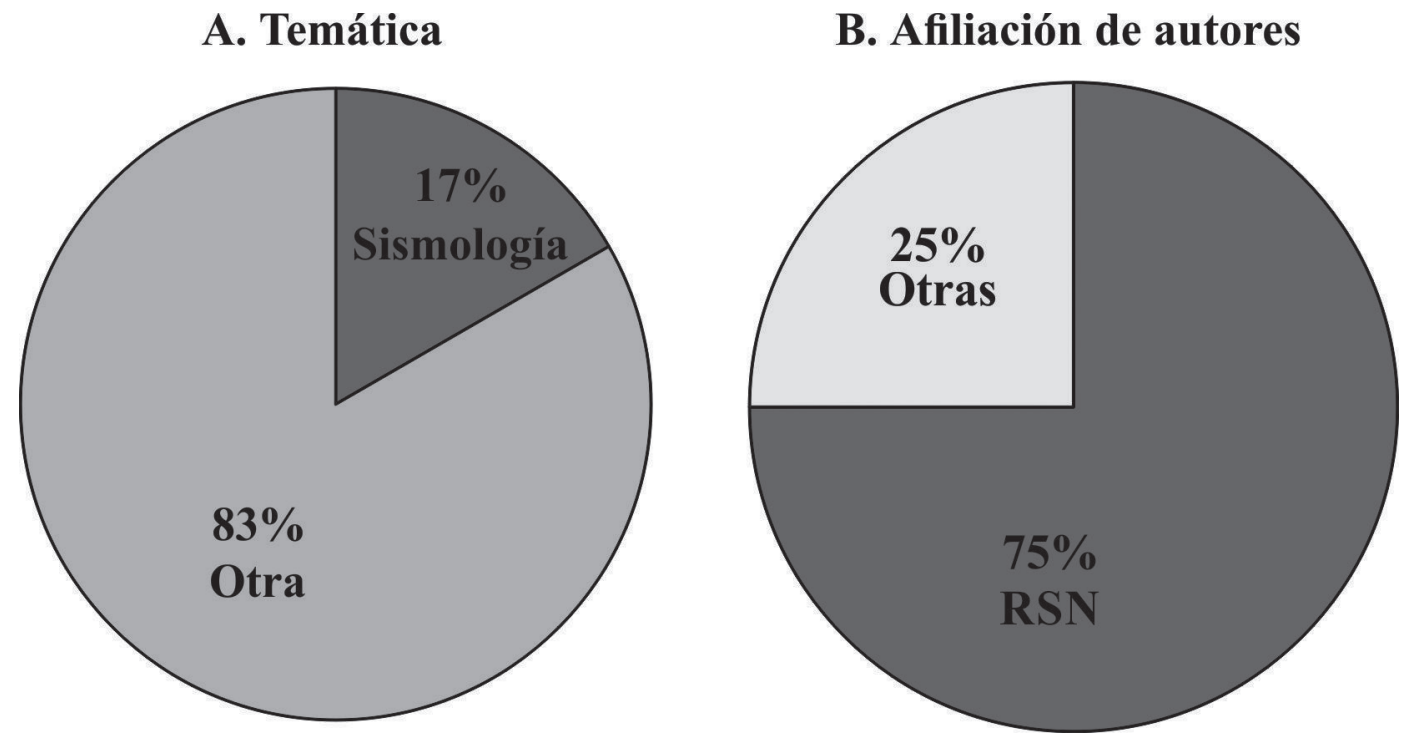

Fig. 3: A) Porcentaje de publicaciones con temática de Sismología versus otras temáticas en la RGAC entre 1984 y 2014 . B) Porcentaje de publicaciones con temática de Sismología de la RGAC en las cuales la afiliación de los autores es RSN (UCR-ICE) versus otras afiliaciones.

de Nicoya (Montero \& Denyer, 2011) y Puriscal (Montero \& Rojas, 2014). Otros aportes incluyen la primera relación entre la aceleración pico del terreno (PGA) y la escala Mercalli Modificada para Costa Rica (Linkimer, 2008a) y la aplicación de métodos de interpolación para el dibujo automatizado de mapas de intensidades (Linkimer, 2008b).

\section{EL REPORTE DE SISMOS SENTIDOS DE LA RSN}

Desde julio de 1976 la RSN lleva un registro continuo de todos los sismos percibidos por la población. La base de datos de sismos sentidos de la RSN, analizada en este artículo, está constituida por 3363 sismos localizados y reportados por la RSN como sentidos, durante el periodo comprendido entre el 28 de julio de 1976 y el 31 de diciembre del 2013 (Fig. 4). El catálogo total de sismos de la RSN está compuesto por 100269 sismos localizados para el periodo del 4 de noviembre de 1974 al 31 de diciembre del 2013, de los cuales 87508 son sismos locales (i.e., ubicados dentro del territorio de Costa Rica). En este artículo examinamos únicamente los sismos que fueron reportados como percibidos por la población, los cuales suelen ser los de mayor magnitud o con epicentros ubicados cerca de áreas pobladas. Para construir la base datos de sismos sentidos se compiló la información contenida en todos los boletines mensuales y anuales divulgados por la RSN durante el periodo 1976-2013 y se corroboró esta información con el catálogo total de sismos localizados.

La difusión del reporte de sismos sentidos por parte de la RSN comienza a partir de julio de 1976. Antes del desarrollo del internet, la RSN solía brindar la información de sismos sentidos por medio del fax a los medios de comunicación colectiva y a la CNE, por lo que el proceso era lento y de distribución limitada. Desde sus inicios en 1976, el contenido de un reporte de un sismo sentido ha incluido los siguientes parámetros: fecha, hora, localización geográfica del epicentro, profundidad del hipocentro, magnitud, intensidades o los sitios donde fue percibido y el origen del sismo.

A partir del 2003, se crea la primera página web de la RSN (www.rsn.ucr.ac.cr) en la que se comienza a publicar la información de sismos sentidos y contenidos relacionados con la sismología. 


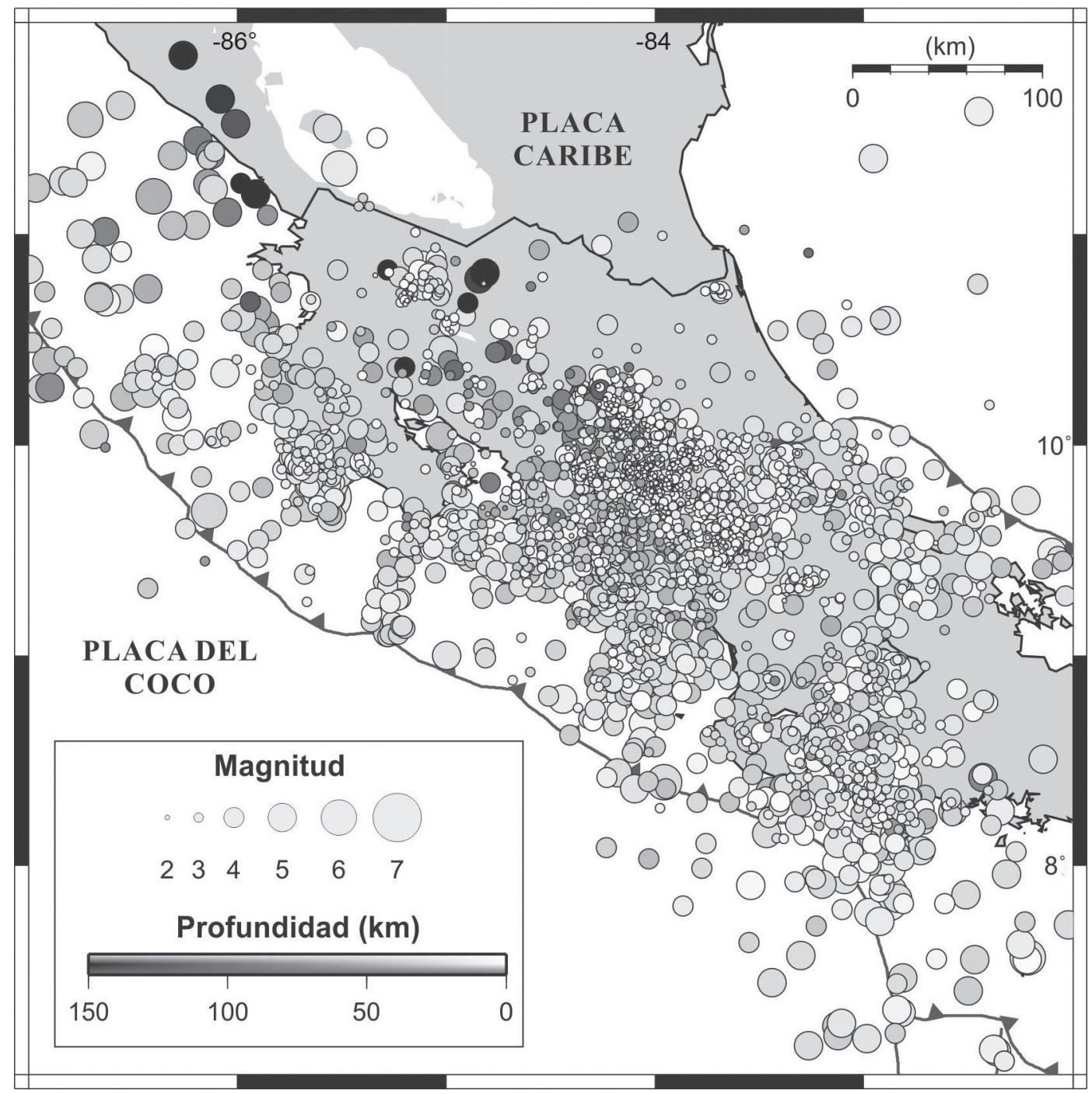

Fig. 4: Mapa epicentral de los sismos sentidos en Costa Rica reportados por la RSN desde julio de 1976 hasta diciembre del 2013.

Paralelamente, comienza el envío de información vía correo electrónico a los medios de comunicación. Actualmente, el contenido generado para el reporte de un sismo sentido es divulgado mediante varias plataformas de información que permiten contactar a gran cantidad de personas. El 2 de enero del 2012 se crean las cuentas de Facebook (https://www.facebook.com/RSN.CR) y Twitter (https://twitter.com/RSNcostarica) de la RSN y a partir de ese momento, comienza a brindarse la información de sismos sentidos por estos medios (Lücke \& Linkimer, 2014).
Dependiendo de la plataforma de divulgación, el contenido del sismo sentido se presenta en distintas versiones: una versión extendida en la página web y una versión resumida en el Facebook y Twitter (Lücke \& Linkimer, 2014). La versión de la página web tiene la ventaja de que no tiene restricciones de espacio, por lo que se puede profundizar más en aspectos como la fuente que originó el sismo y los sitios donde fue percibido. Adicionalmente, en la página web es posible colocar figuras como el mapa epicentral, sismogramas, mapas de réplicas, etc. En el 
caso de las redes sociales, se presenta el reporte de manera resumida con menos de 140 caracteres y con énfasis en los parámetros primordiales que caracterizan un sismo, como son: la fecha y hora, la localización del epicentro, la profundidad y la magnitud. Asimismo, en las redes sociales se ofrece un enlace a la página web en caso de que el usuario esté interesado en una descripción más detallada (Lücke \& Linkimer, 2014).

\section{DISTRIBUCIÓN TEMPORAL Y POR MAGNITUD Y PROFUNDIDAD}

La cantidad anual de sismos sentidos reportados por la RSN ha variado entre 15 y 353 (Fig. 5A). Los años con la mayor cantidad de sismos sentidos fueron 1991, 2012 y 2013, con 353, 264 y 261, sismos, respectivamente. En los años de 1990 y 1983, la cantidad de sismos sentidos también fue importante con 191 y 185 , respectivamente. La gran cantidad de sismos sentidos de los años mencionados se debe a la ocurrencia de terremotos, sus réplicas y sismos inducidos. Los sismos más significativos de los años mencionados son los terremotos de Golfito del 2 de abril de 1983 ( M 7,3), Buenavista de Pérez Zeledón del 3 de julio de $1983\left(\mathrm{M}_{\mathrm{w}}\right.$ 6,2), Limón del 22 de abril de $1991\left(M_{w} 7,7\right)$, Cóbano del 25 de marzo de $1990\left(M_{w} 7,0\right.$ y 7,1), Alajuela del 22 de diciembre de $1990\left(M_{w} 6,0\right)$ y Sámara del 5 de septiembre del $2012\left(M_{w}\right.$ 7,6) el cual provocó una alta sismicidad que se prolongó hasta el 2013.

Los años con la menor cantidad de sismos sentidos fueron 1976, 1981 y 1977, con únicamente 15, 20 y 23 sismos, respectivamente. Es importante mencionar que el catálogo de sismos sentidos de la RSN antes de 1990 contiene un número menor de sismos sentidos en comparación con los años posteriores. Esto se debe a que a partir de 1990 se incrementó la cobertura de estaciones sismológicas a nivel nacional y se comenzó a procesar los sismos de forma automatizada con ayuda de mejores programas de cómputo. Otro paso importante se dio a partir de enero del 2012, cuando la RSN incursionó en el reporte de los sismos a través de las redes sociales Facebook y Twitter. Con ello mejoró la realimentación de los usuarios pues a través de estos nuevos canales de comunicación, con los cuales se obtiene con facilidad reportes sobre dónde y cómo fueron percibidos los sismos. Adicionalmente, el crecimiento de la población y el incremento en el acceso al internet propicia el aumento de reportes de sismos sentidos. Todo esto podría dar una falsa sensación de un aumento en la sismicidad.

El promedio anual de sismos que fueron percibidos por la población de Costa Rica para el periodo 1976-2013 es de 90,5. Esto implica que el promedio mensual es de 7,5, el promedio semanal es de 1,9 y que en algún punto de Costa Rica fue reportado sentido un temblor cada 5 días. Es importante aclarar que estos promedios son muy sensibles a la región y periodo de observación pues el número de sismos sentidos depende no solo del nivel natural de la sismicidad, sino de otros factores que se mencionaron en párrafos anteriores como la cantidad de población expuesta, la capacidad de detección de sismos por parte de la red (i.e. cobertura de estaciones, sistemas de localización, disponibilidad del personal) y de la eficiencia de los canales de comunicación tanto de la RSN y como de los usuarios. Por ejemplo, Morales \& Montero (1984) analizaron los temblores sentidos en el Área Metropolitana de San José entre 1973 y 1983 y encontraron que el promedio de sismos sentidos para esa zona y periodo era de 14,7 temblores por año.

El mes del año con más reportes de sismos sentidos ha sido abril con 406 (Fig. 6A). Esto se debe a que dos grandes terremotos ocurrieron ese mes: el terremoto de Golfito del 2 de abril de 1983 $\left(\mathrm{M}_{\mathrm{w}} 7,3\right)$ y el terremoto de Limón del 22 de abril de $1991\left(M_{w}\right.$ 7,7). El mes del año con menos reportes de sismos sentidos ha sido febrero con 213 (Fig. 6A) y coincide con que febrero es el mes con menos días del año y durante el periodo 19762013 no ocurrió un terremoto durante ese mes. Con respecto al día del mes, los días 23,9 y 26 , son los que han presentado más sismos sentidos, con 152, 138 y 136 (Fig. 6B). Estas "anomalías" se correlacionan con las réplicas del día siguiente a los terremotos de Limón de 1991 (día 22), Cinchona en el 2009 (día 8) y Cóbano en 1990 (día 25). El día con menos sismos sentidos es el 


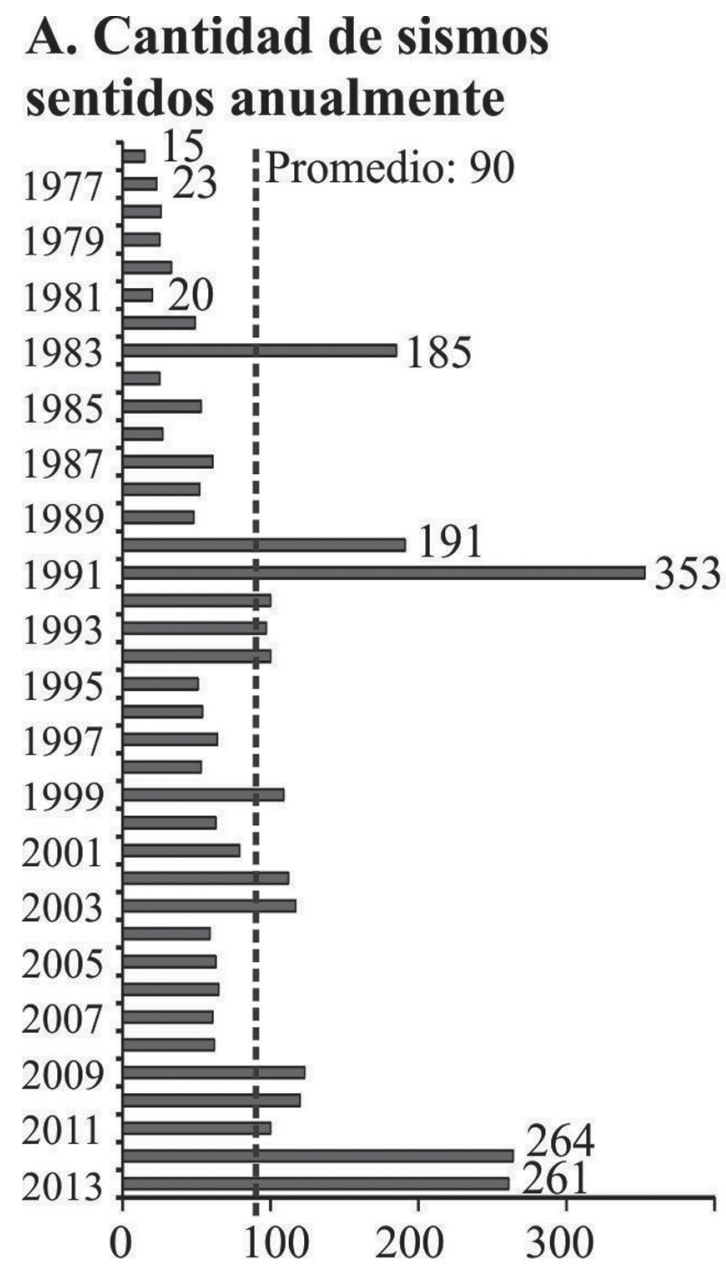

\section{B. Cantidad de sismos sentidos en Semana Santa}

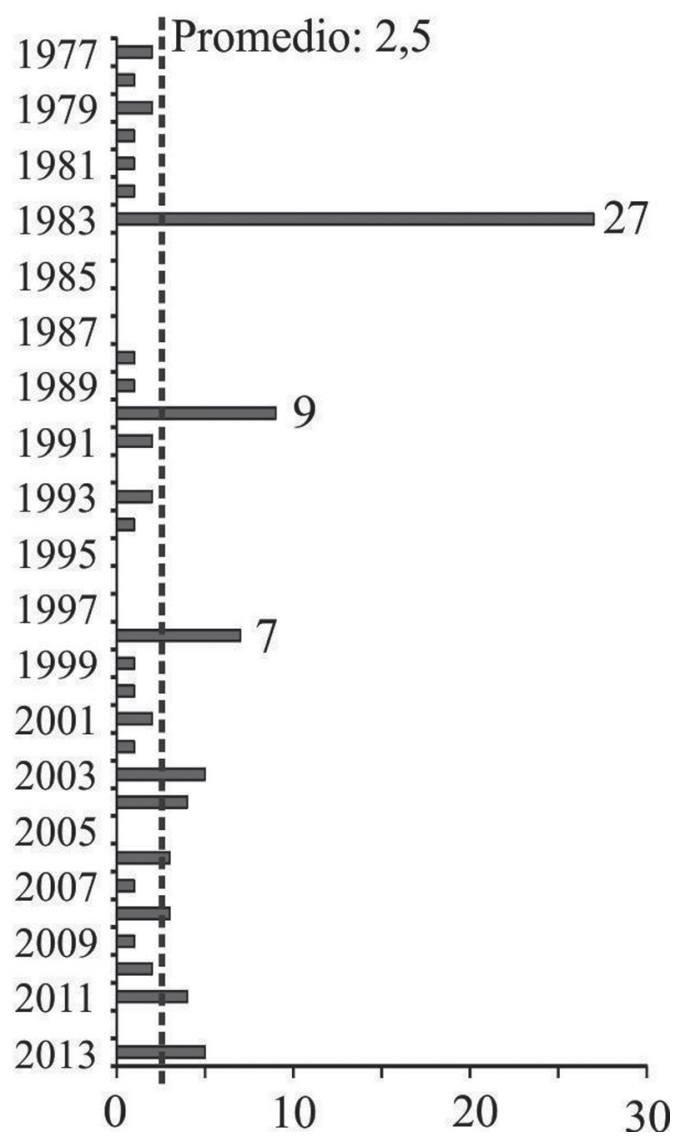

Fig. 5: A. Cantidad de sismos sentidos por año. B. Cantidad de sismos sentidos durante los períodos de Semana Santa. Línea discontinua marca el valor promedio de sismos por año para cada histograma.

día 31, con sólo 57. Esta baja nuevamente corresponde con el hecho de que de los 12 meses del año, sólo 7 meses poseen día 31.

La hora local del día con más temblores sentidos durante 1976-2013 es entre las 2:00 y 2:59 a.m., con 168 sismos y luego entre la 1:00 y 1:59 a.m., con 164 sismos (Fig. 6C). El promedio del total de sismos para cada hora es de 140. Curiosamente, las horas de la madrugada, entre la 1:00 y 5:59 am se encuentran todas sobre el promedio de 140 sismos (Fig. 6C). Esto podría explicarse debido a una mayor percepción de los sismos durante la quietud de la madrugada, cuando la mayoría de las personas se encuentran en reposo. La hora con menos reportes de sismos sentidos se presenta entre las 10:00 y las 10:59 pm.
En Costa Rica existe la creencia en parte de la población de que la sismicidad es alta durante la Semana Santa. En los registros de la RSN consta únicamente un pico de sismicidad durante dicha semana en 1983, cuando se presentó el terremoto de Golfito o del Sábado Santo (Fig. 5B). Otros sismos sentidos se presentaron durante la Semana Santa de los años 1990 y 1998, cuando se registraron 9 y 7 sismos, respectivamente. En los años restantes del registro de la RSN se cuentan muy pocos sismos durante la Semana Santa (menos de 5), incluyendo 10 años en los cuales no se reportaron sismos sentidos del todo. El promedio de sismos sentidos para la Semana Santa de todos los años en el periodo de 1977-2013 es de 2,5 sismos, 


\section{A. Sismos sentidos por mes}

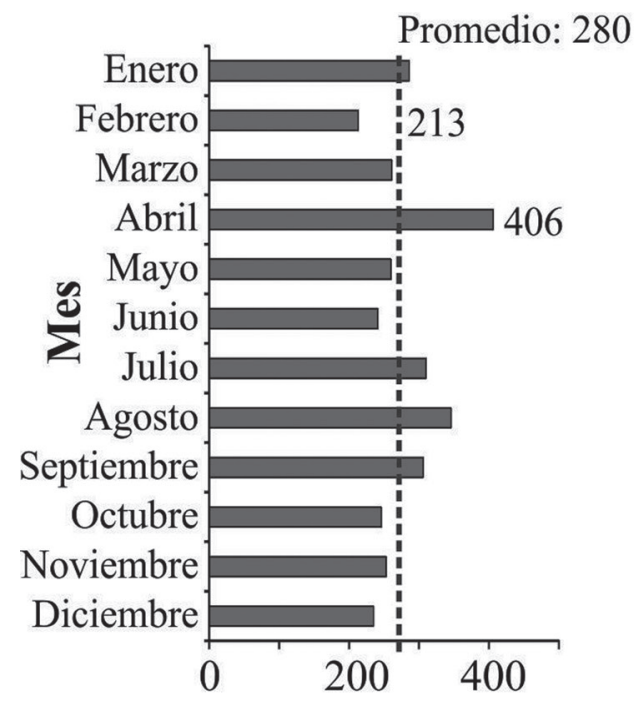

\section{B. Sismos sentidos por día}

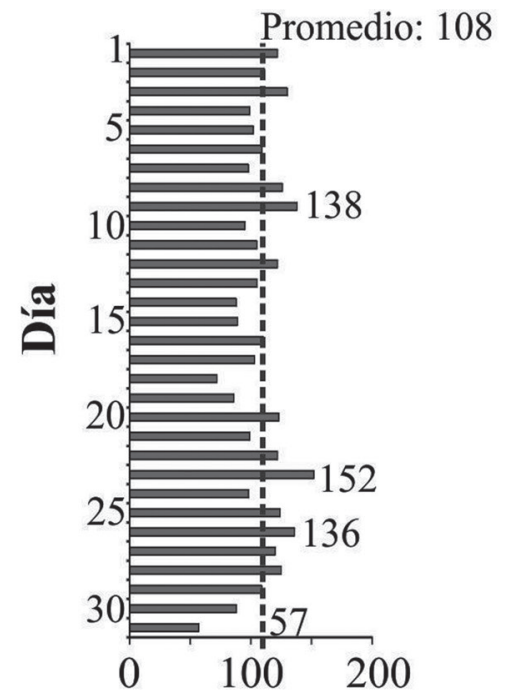

\section{Sismos sentidos por hora}

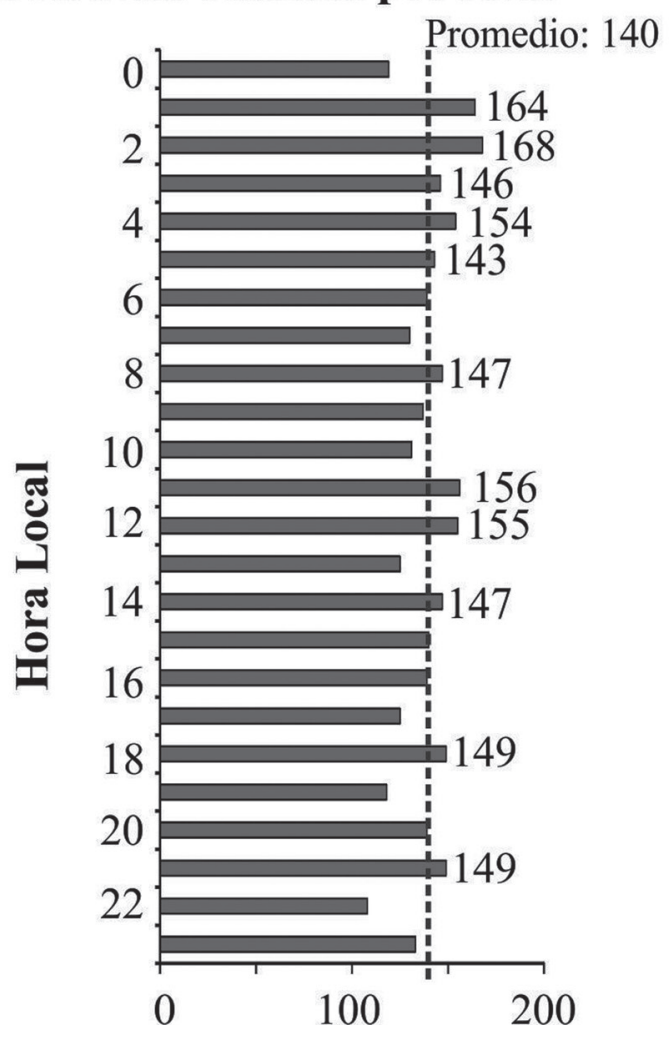

Fig. 6: A. Cantidad total de sismos sentidos por mes durante el periodo 1976-2013. B. Cantidad total de sismos sentidos por día durante el periodo 1976-2013. C. Cantidad total de sismos sentidos por hora durante el periodo 1976-2013. Las líneas discontinuas marcan el valor promedio de sismos en cada histograma. 
el cual disminuye a 1,8 si no se toma en cuenta la Semana Santa de 1983. Esta cantidad es muy similar al promedio semanal de sismos sentidos para el periodo de 1977 al 2013 usando toda la base de datos, el cual es de 1,9. Con excepción de 1983, la Semana Santa del resto de años no representa una "anomalía" en la cantidad de sismos sentidos. La percepción de la población de la alta sismicidad en Semana Santa proviene de la experiencia vivida por el terremoto de Golfito que ocurrió justamente cuando muchas personas se encontraban escuchando misa (8:50 pm).

La base de datos de sismos sentidos también incluye sismos distantes que han sido percibidos en el territorio costarricense. El sismo más distante que ha sido percibido en Costa Rica durante el periodo 1976-2013, ocurrió en Bolivia el 8 de junio de 1994. Este sismo tuvo una magnitud $\mathrm{M}_{\mathrm{w}}$ de 8,3 y una profundidad de $637 \mathrm{~km}$. El sismo fue percibido levemente en edificios altos de San José e incluso fue percibido en Canadá. Otro sismo regional que fue sentido en Costa Rica fue el terremoto de El Salvador del 13 de enero del $2001\left(M_{w} 7,6\right)$ el cual fue percibido con intensidad Mercalli Modificada (MM) de III en San José y IV en Guanacaste.

Para el análisis de la distribución de los sismos por magnitud y profundidad, se utilizaron solamente los sismos ubicados entre las coordenadas 7 y 12 latitud norte y 82 y 87 longitud oeste, con el objetivo de detallar las características de los sismos que ocurren dentro del territorio costarricense o muy cerca de sus límites. Es importante mencionar que algunos de los primeros sismos reportados por la RSN durante sus primeros años de funcionamiento carecen del dato exacto de magnitud y profundidad. Por esta razón la cantidad total de sismos sentidos que se analizan para la distribución de magnitud es de 3289 y para profundidad de 3267.

Con respecto a la magnitud, la mayoría de los sismos sentidos (47\%) han tenido magnitudes de entre 3,0 y 3,9 (Fig. 7A). Los sismos con magnitudes de entre 4,0 y 4,9 representan el 37,6\% del total de sismos sentidos. Los microsismos (i.e., magnitudes menores a 2,9) corresponden con el
$8,3 \%$ de la totalidad de los sismos sentidos. Estos pequeños eventos son percibidos cuando son superficiales $(<10 \mathrm{~km})$ y se localizan cerca de centros de población y por esta razón se concentran geográficamente principalmente en la parte central del país donde se ubica el Área Metropolitana de San José (Fig. 8A).

Durante el periodo analizado, 205 sismos sentidos han tenido una magnitud de entre 5,0 y 5,9 (Fig. 8D) y 23 sismos una magnitud de entre 6,0 y 6,9 (Fig. 8E). Estos números implican que en Costa Rica durante el periodo de observación se han sentido en promedio 5 sismos de magnitud de entre 5,0 y 5,9 por año y un sismo de magnitud de entre 6,0 y 6,9 cada dos años (Fig. 7A). Cinco terremotos han sobrepasado la magnitud de 7,0 entre 1976 y el 2013. Estos fueron los terremotos de Golfito del 2 de abril de $1983\left(\mathrm{M}_{\mathrm{w}} 7,3\right)$, Cóbano del 25 de marzo de $1990\left(\mathrm{M}_{\mathrm{w}} 7,0\right.$ y 7,1), Limón del 22 de abril de $1991\left(\mathrm{M}_{\mathrm{w}} 7,7\right)$ y Sámara del 5 de septiembre del $2012\left(M_{w}\right.$ 7,6). Desde 1821, año en que Costa Rica adquiere su independencia, el país ha sufrido 67 sismos destructivos (terremotos), de los cuales 14 han tenido magnitudes mayores a 7,0. Esto implica un promedio de un sismo destructivo cada 3 años y un terremoto de magnitud mayor a 7,0 cada 14 años.

La mayoría $(83,7 \%)$ de los sismos sentidos fueron superficiales, con hipocentros menores a $30 \mathrm{~km}$ (Fig. 7B). Como es de esperar debido a la atenuación de las ondas sísmicas, conforme aumenta la profundidad de los hipocentros, menor es la cantidad de sismos que son percibidos por la población. Solamente 9 sismos con profundidades mayores a $150 \mathrm{~km}$ han sido percibidos entre 1976 y el 2013, todos con epicentros al oeste y sur del lago de Nicaragua (Fig. 4 y 7B).

\section{DISTRIBUCIÓN ESPACIAL Y POR ORIGEN}

En este apartado analizamos la distribución espacial y el origen de 87 sismos de magnitudes mayores a 5,5 durante el periodo 1976-2013 y ubicados entre las coordenadas 7 y 12 latitud norte y 82 y 87 
A. Sismos sentidos por magnitud

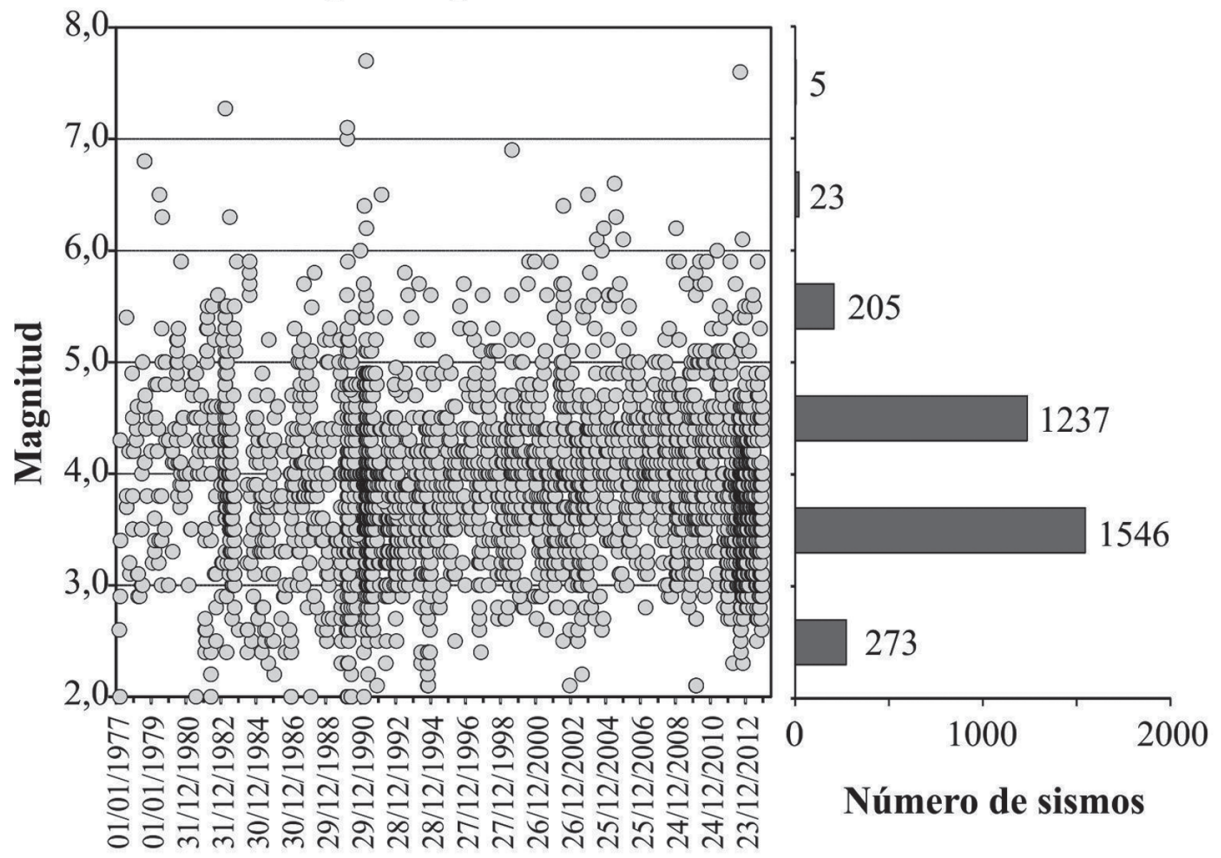

Fecha

\section{B. Sismos sentidos por profundiad}

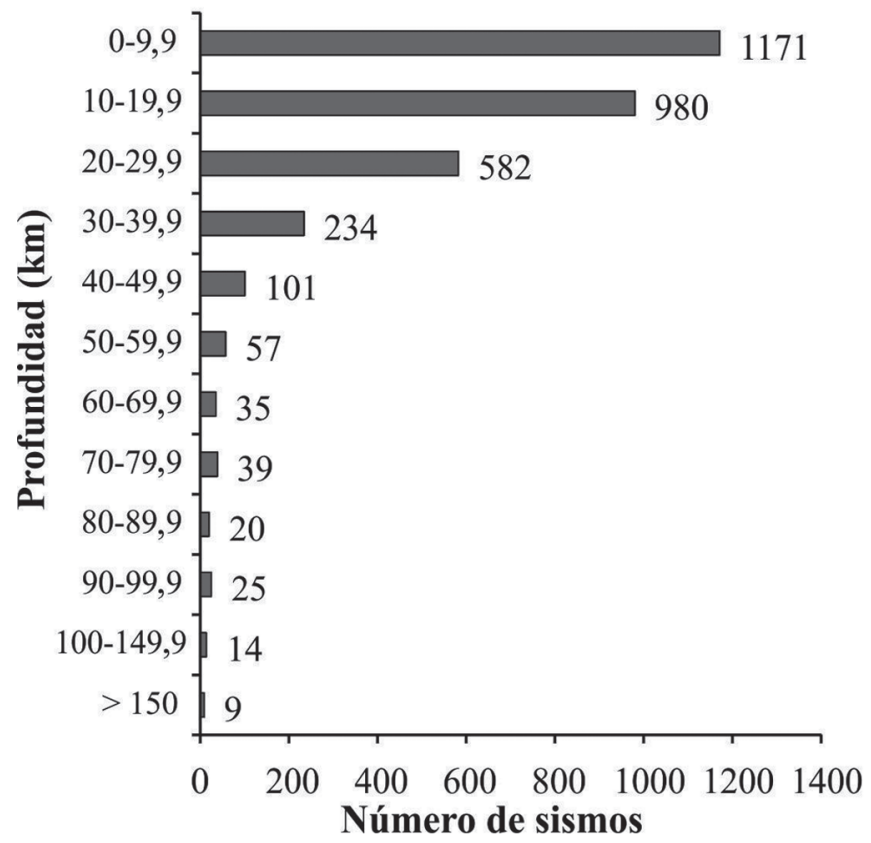

Fig. 7: Cantidad de sismos sentidos de acuerdo con su magnitud (A) y profundidad (B) durante el periodo 1976-2013. 


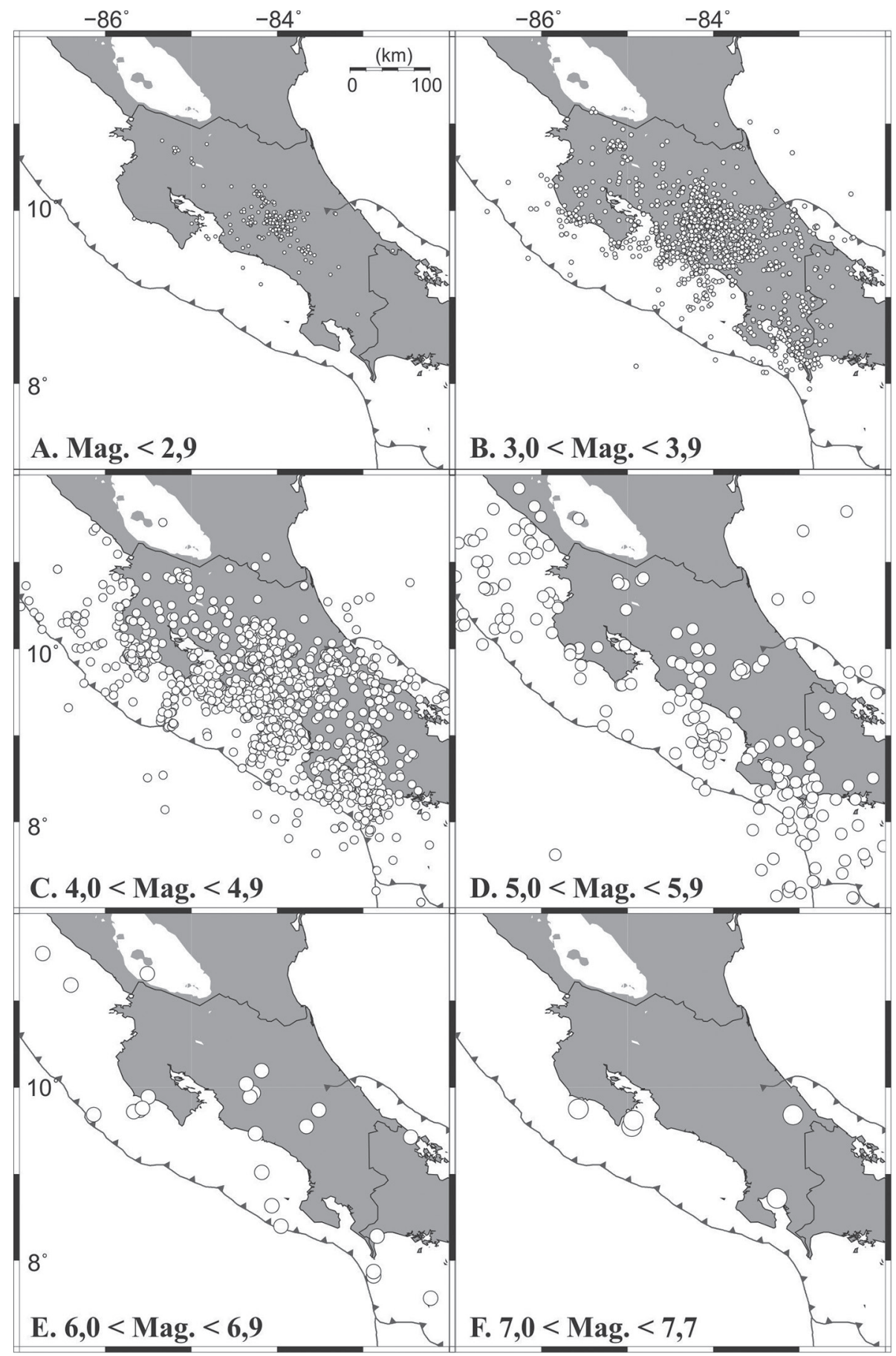

Fig. 8: Mapas epicentrales de los sismos sentidos en Costa Rica reportados por la RSN durante el periodo de 1976 hasta el 2013 de acuerdo con su magnitud. 


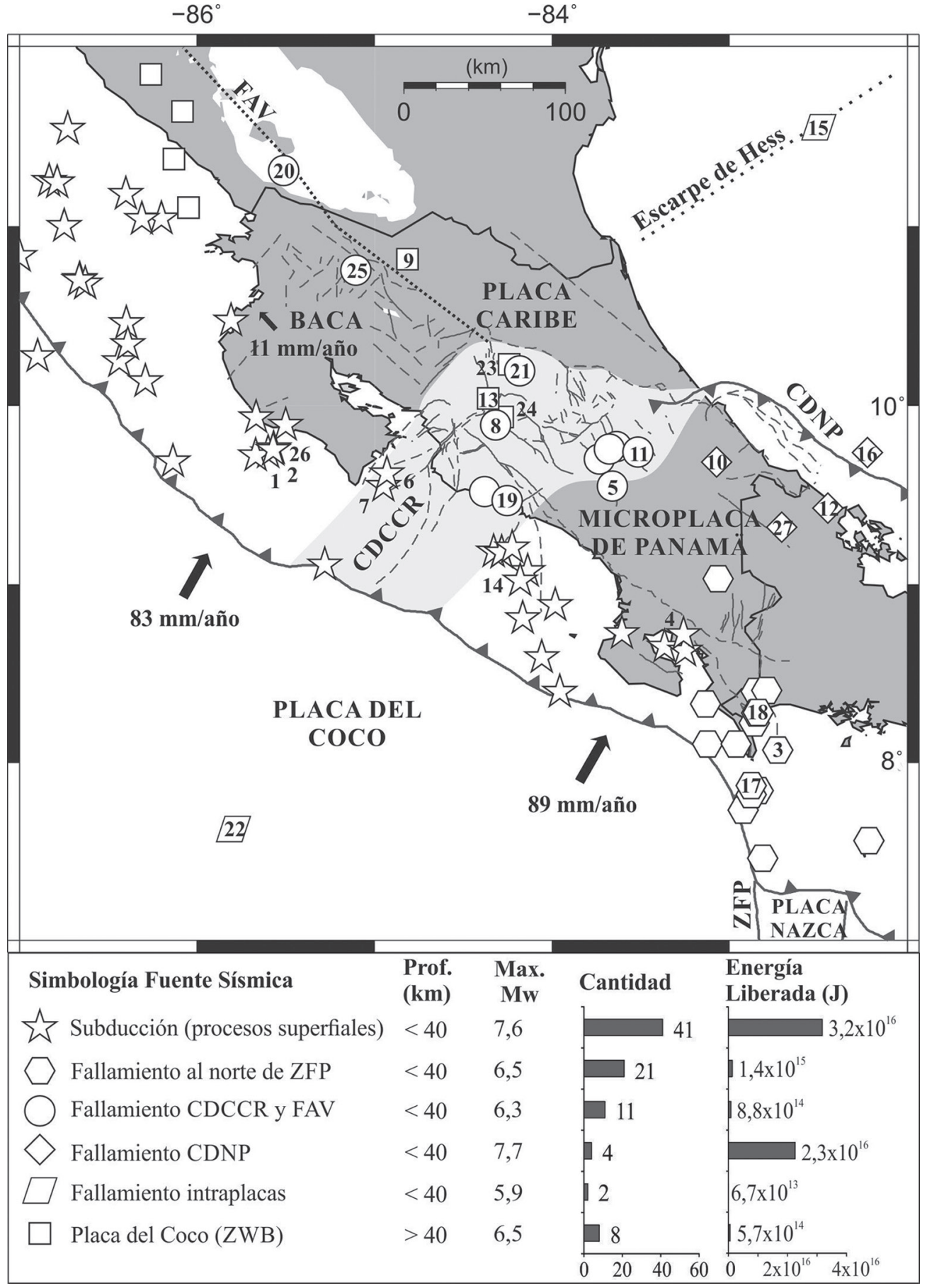

Fig. 9: Origen de los sismos de magnitud mayor a 5,5 en Costa Rica que ocurrieron en el periodo 1976-2013. Los sismos numerados se encuentran referidos en Cuadro 1. BACA significa Bloque Antearco Centroamericano. Ver Fig.1 para explicación de otros acrónimos y símbolos. 
longitud oeste (Fig. 9). Estos sismos son los más significativos debido a su tamaño e intensidades generadas en Costa Rica y representan el 98.2\% (i.e., 5,72 x $1016 \mathrm{~J}$ ) del total de la energía liberada por los 3363 sismos que conforman la base de datos de sismos sentidos de la RSN (i.e., 5,83 x $1016 \mathrm{~J})$. El origen de estos sismos puede separarse en seis fuentes sísmicas diferentes (Fig. 9): procesos superficiales de la subducción de la placa del Coco (41 sismos), fallamiento en región al norte de la ZFP (21 sismos), fallamiento en el CDCCR y arco volcánico (11 sismos), fallamiento relacionado con el CDNP (4 sismos), fallamiento en el interior de las placas Caribe y del Coco ( 2 sismos) y deformación interna de la placa del Coco en la Zona de Wadati-Benioff (8 sismos).

Los sismos que ocurren por subducción de la placa del Coco están distribuidos a lo largo de la costa Pacífica de Costa Rica y Nicaragua (Fig. 9). Estos sismos pueden tener su origen en varias procesos a nivel superficial (profundiad $<40 \mathrm{~km}$ ) del sistema de subducción como por ejemplo la zona sismogénica (i.e., zona de acople interplacas), la zona del levantamiento (outer rise) y en la cuña cortical de la placa cabalgante. Debido a la incertidumbre en la estimación de la profundidad de muchos de los sismos que ocurren en la costa Pacífica por estar fuera de la cobertura de la red, es difícil discriminar en cual parte del sistema de subducción ocurren exactamente y por esto la descripción de los mismos se realiza en conjunto en este articulo. En total, 41 sismos de magnitud mayor a 5,5 han sido originados por los procesos superficiales de la subducción de la placa del Coco, lo cual representa el 54,5\% del total de energía liberada por los sismos sentidos en el periodo analizado. Estos sismos incluyen cuatro (de los cinco) terremotos de magnitud mayor a 7,0 que han ocurrido en el periodo 1976-2013 (Fig. 9, Cuadro 1). Estos cuatro eventos ocurrieron en la zona sismogénica y se conocen como los terremotos de Golfito del 2 de abril de 1983 ( $\mathrm{M}_{\mathrm{w}}$ 7,3, Bilek et la., 2003), de Cóbano del 25 de marzo de $1990\left(M_{w} 7,0\right.$ y 7,1 Husen et al., 2002, Bilek et la., 2003) y Sámara del 5 de septiembre del 2012 ( $\mathrm{M}_{\mathrm{w}}$ 7,6, Linkimer et al., 2013; Protti et al., 2014). Otros tres eventos significativos por su magnitud son el terremoto de Quepos del 20 de agosto de
1999 ( $\mathrm{M}_{\mathrm{w}}$ 6,9, Rojas \& Redondo, 2002; Bilek et la., 2003) y los dos terremotos de Sámara del 22 de agosto de $1978\left(M_{w} 6,8\right)$. La frecuencia y cantidad de energía liberada de los eventos originados por los procesos superficiales de la subducción de la placa del Coco es la más alta en relación con el resto de las fuentes sísmicas. En promedio durante el periodo analizado ocurrió un sismo de magnitud mayor a 5,5 cada año en algún punto de la costa Pacífica.

La segunda fuente sismogeneradora en importancia por la cantidad de eventos sentidos es el fallamiento en la zona ubicada al norte de la ZFP, la cual abarca la península de Burica y la región entre esta península y el punto triple entre las placas del Coco y Nazca y la Microplaca de Panamá (Fig. 9). En esta zona ocurrieron 21 sismos de magnitudes mayores a 5,5 durante el periodo analizado, lo cual representa únicamente el 2,3\% del total de energía liberada durante el periodo analizado. Esto se debe a que las magnitudes de los sismos han sido de menor tamaño que los ocurridos por la subducción de la Placa del Coco. Los sismos de mayor tamaño en esta zona fueron los ocurridos el 25 de diciembre del 2003 (terremoto de Navidad, $\mathrm{M}_{\mathrm{w}}$ 6,5), el 1 de julio de $1979\left(\mathrm{M}_{\mathrm{w}} 6,5\right)$ y el 30 de julio del 2002 $\left(M_{w} 6,4\right)$. La fuente de estos sismos corresponde con fallas de desplazamiento de rumbo dextral de rumbo norte-sur e inversas en segmentos que se curvan hacia el noroeste y que se ubican en la microplaca de Panamá. Estas fallas son la respuesta del anterarco a la subducción de la ZFP, la cual es una gran falla dextral que sirve de límite entre las placas del Coco y Nazca (Corrigan et al., 1990; Morrell et al., 2008; Morrell et al., 2011) y que ha originado grandes terremotos como el del 18 de julio de 1934 ( $\mathrm{M}_{\mathrm{w}}$ 7,6, Camacho, 1991).

Once sismos de magnitud mayor a 5,5 han ocurrido debido al fallamiento en el CDCCR y el arco volcánico (Fig. 9). Esto representa el 1,5\% del total de energía liberada durante el periodo analizado. El CDCCR corresponde con una zona de deformación de aproximadamente $100 \mathrm{~km}$ de ancho, que atraviesa transversalmente al país desde la fosa Mesoamericana en el lado Pacífico, hasta el CDNP en el sector Caribe (Marshall et al., 2000; Montero, 2001) y que sirve de límite 
Cuadro 1

Origen de los sismos de magnitud mayor a 5,5 discutidos en el texto (Fig. 9)

\begin{tabular}{|c|c|c|c|c|c|}
\hline N. & Fecha & Nombre & Mw & Fuente sísmica & Referencia \\
\hline 1 & $22-08-1978$ & Sámara & 6,8 & Subducción & \\
\hline 2 & $22-08-1978$ & Sámara & 6,8 & Subducción & \\
\hline 3 & 01-07-1979 & Armuelles & 6,5 & ZFP & \\
\hline 4 & $02-01-1983$ & Golfito & 7,3 & Subducción & Bilek et al. (2003) \\
\hline 5 & 03-07-1983 & Pérez Zeledón & 6,3 & CDCCR & Boschini et al. (1988) \\
\hline 6 & $25-03-1990$ & Cóbano & 7,0 & Subducción & Husen et al. (2002) \\
\hline 7 & $25-03-1990$ & Cóbano & 7,1 & Subducción & Husen et al. (2002) \\
\hline 8 & $22-12-1990$ & Alajuela & 6,0 & Alajuela & Montero \& Rojas (2014) \\
\hline 9 & 01-03-1990 & Guatuso & 5,7 & ZWB & \\
\hline 10 & 22-04-1991 & Limón & 7,7 & CDNP & Goes et al. (1993) \\
\hline 11 & 24-04-1991 & Tayutic & 6,2 & CDCCR & Fan et al. (1993) \\
\hline 12 & 03-05-1991 & Changuinola & 6,2 & CDNP & Fan et al. (1993) \\
\hline 13 & 06-03-1992 & Naranjo & 6,5 & ZWB & \\
\hline 14 & 20-08-1999 & Quepos & 6,9 & Subducción & Rojas \& Redondo (2002) \\
\hline 15 & $13-08-2000$ & P. Caribe & 5,9 & Intraplaca & RSN (2001) \\
\hline 16 & $08-11-2001$ & Sixaola & 5,9 & CDNP & RSN (2002) \\
\hline 17 & $30-07-2002$ & Burica & 6,4 & ZFP & \\
\hline 18 & $25-12-2003$ & Armuelles & 6,5 & ZFP & \\
\hline 19 & 20-11-2004 & Parrita & 6,2 & CDCCR & Pacheco et al. (2006) \\
\hline 20 & $03-08-2005$ & Ometepe & 6,3 & FAV & French et al. (2010) \\
\hline 21 & 08-01-2009 & Cinchona & 6,2 & CDCCR & RSN (2009) \\
\hline 22 & $13-08-2009$ & P. del Coco & 5,7 & Intraplaca & Barquero \& Rojas (2010) \\
\hline 23 & $08-10-2010$ & Zarcero & 5,9 & ZWB & Barquero \& Rojas (2011) \\
\hline 24 & $13-05-2011$ & Turrúcares & 6,0 & ZWB & Barquero et al. (2012) \\
\hline 25 & $12-07-2011$ & Las Armenias & 5,5 & FAV & Taylor et al. (2012) \\
\hline 26 & $05-09-2012$ & Sámara & 7,6 & Subducción & Protti et al. (2014) \\
\hline 27 & $27-05-2013$ & Sixaola & 5,6 & CDNP & \\
\hline
\end{tabular}

CDCCR: Cinturón Deformado del Centro de Costa Rica, CDNP: Cinturón Deformado del Norte de Panamá, FAV: Fallamiento en el Arco Volcánico, ZFP: fallamiento en región al norte de la Zona de Fractura de Panamá, ZWB: deformación interna de la placa del Coco en la Zona de Wadati-Benioff.

entre la placa Caribe y la microplaca de Panamá. Adicionalmente, a lo largo del arco volcánico desde el norte de Costa Rica y hasta Guatemala, existen fallas principalmente de desplazamiento de rumbo que acomodan el movimiento del llamado Bloque del Antearco Centroamericano (BACA) que se mueve hacia el noroeste en forma paralela a la trinchera con velocidades de $8-17 \mathrm{~mm} / \mathrm{año}$ (LaFemina et al., 2009; French et al., 2010; Ye et al., 2013; Kobayashi et al., 2014). Estas fallas son modeladas como la Falla del Arco Volcánico (FAV) que no corresponde con una falla sencilla, sino con un conjunto de fallas de diversa geometría ubicadas a lo largo del arco volcánico y que limitan el BACA hacia el noreste (DeMets, 2001; Correa-Mora et al., 2009; Franco et al., 2012). Los sismos originados en el CDCCR tienen especial relevancia por su cercanía con las zonas más po- 
bladas de Costa Rica. Destacan durante el periodo 1976-2013 los terremotos de Buenavista de Pérez Zeledón del 3 de julio de 1983 ( $\mathrm{M}_{\mathrm{w}}$ 6,2, Boschini et al., 1988; Mora \& Peraldo, 2011), Alajuela o Piedras Negras del 22 de diciembre de $1990\left(\mathrm{M}_{\mathrm{w}}\right.$ 6,0, Montero \& Rojas, 2014), Tayutic de Turrialba del 24 de abril de 1991 ( $\mathrm{M}_{\mathrm{w}}$ 6,2, Fan et al., 1993; Suárez et al., 1995), Damas del 20 de noviembre del $2004\left(\mathrm{M}_{\mathrm{w}}\right.$ 6,2, Pacheco et al., 2006) y Cinchona del 8 de enero del 2009 ( $\mathrm{M}_{\mathrm{w}}$ 6,2) (RSN, 2009). Fuera del CDCCR, en el arco volcánico se presentaron dos eventos importantes: el sismo de Las Armenias del 12 de julio del $2011\left(\mathrm{M}_{\mathrm{w}}\right.$ 5,5, Barquero et al., 2012; Taylor et al., 2012) y en la isla de Ometepe del lago de Nicaragua muy cerca del límite con Costa Rica el 3 de agosto del 2005 $\left(\mathrm{M}_{\mathrm{w}}\right.$ 6,3, French et al., 2010).

El fallamiento relacionado con el CDNP ha sido el origen de cuatro sismos de magnitud mayor a 5,5 durante el periodo 1976-2013 lo que representan el 38,7\% del total de la energía liberada durante el periodo analizado (Fig. 9). El evento más importante fue el terremoto de Limón del 22 de abril de 1991 (Goes et al., 1993; Suárez et al., 1995; Barquero \& Rojas, 1994; Montero et al., 1994a, 1994b, Ponce et al., 1994) que con una magnitud $\mathrm{M}_{\mathrm{w}}$ de 7,7 ha sido el sismo más grande del periodo analizado y corresponde con el 38,4\% del total de la energía libertada por todos los sismos del periodo estudiado. El terremoto de Limón causó daños en un área de $8000 \mathrm{~km} 2$ que incluyen el $80 \%$ del territorio costarricense y el 20\% del de Panamá (Morales, 1994). Los efectos geológicos más notables fueron el levantamiento de la línea de costa del Caribe (Denyer et al., 1994a, 1994b; Denyer et al., 2003), la licuefacción y hundimientos costeros (Camacho \& Víquez, 1994; Mora \& Yasuda, 1994), los deslizamientos (Mora \& Mora, 1994) y un tsunami local con olas de hasta $2,0 \mathrm{~m}$ (Camacho, 1994). Otros terremotos históricos del CDNP ocurrieron en 1822, 1904 (?), 1916 y 1953 (Camacho \& Víquez, 1993; Boschini \& Montero, 1994). Los otros tres sismos significativos del periodo analizado ocurrieron el 3 de mayo de 1991 ( $\mathrm{M}_{\mathrm{w}}$ 6,2, Fan et al., 1993), el 8 de noviembre del $2011\left(\mathrm{M}_{\mathrm{w}} 5,9, \mathrm{RSN}, 2002\right)$ y el 27 de mayo el $2013\left(M_{w} 5,6\right)$.
Los sismos en el interior de las placas del Coco y Caribe fueron los menos frecuentes con relación al resto de fuentes sísmicas. Solamente dos sismos tuvieron magnitudes mayores a 5,5 y se localizaron alejados (más de $150 \mathrm{~km}$ ) de los límites entre placas pero fueron percibidos en Costa Rica debido a su magnitud. Estos dos sismos representan únicamente el $0,1 \%$ del total de energía liberada durante el periodo analizado (Fig. 9). Uno de ellos ocurrió el 13 de agosto del 2000 $\left(\mathrm{M}_{\mathrm{w}} 5,9, \mathrm{RSN}, 2001\right)$ y se localizó en el interior de la placa Caribe, a $153 \mathrm{~km}$ al noreste de Barra del Colorado en Limón. La estructura tectónica más importante que se localiza cerca de la zona de este epicentro es el Escarpe de Hess, el cual tiene rumbo noreste en el piso oceánico de la placa Caribe y tradicionalmente se ha usado para representar el límite entre bloques geológicos de diversos orígenes, denominados Chortis y Chorotega (Bowland, 1993; Mann et al., 2007). La proyección del Escarpe de Hess en el interior de Costa Rica y su posible localización en tierra es motivo de debate y ha sido sugerido a través de evidencias geológicas y geofísicas (Dengo, 1985; Hauff et al., 2000; MacKenzie et al., 2008; Baumgartner et al., 2008; Linkimer et al., 2010) y por la actividad sísmica en la zona de la isla Calero durante el año 2012 (Linkimer et al., 2014). El otro sismo intraplaca importante ocurrió en el interior de la placa del Coco el 13 de agosto del $2009\left(\mathrm{M}_{\mathrm{w}}\right.$ 5,7 , Barquero \& Rojas, 2010). En este caso, el sismo tuvo su epicentro a $244 \mathrm{~km}$ al suroeste de Cóbano en una región donde no hay estructuras sismogénicas reconocidas con precisión (Fig. 9, Cuadro 1).

Con respecto a los sismos de profundidad intermedia (50-300 km), ocho eventos de magnitudes mayores a 5,5 ocurrieron durante 1976-2013 y representan únicamente el 1,0\% del total de energía liberada (Fig. 9). Estos sismos se originan debido a la deformación interna de la placa del Coco que se subduce bajo Costa Rica, en lo que se conoce como la Zona de Wadati-Benioff (ZWB). La sismicidad en la ZWB está asociada con la deshidratación de la placa que se subduce que induce el comportamiento frágil a estas profundidades (Ranero et al., 2005). Cuatro de estos sismos han ocurrido en la costa Pacífica de 
Nicaragua cerca del límite con Costa Rica. Otro evento ocurrió al sur del lago de Nicaragua el 1 de marzo de $1991\left(\mathrm{M}_{\mathrm{w}}\right.$ 5,7) y ha sido el más profundo $(197 \mathrm{~km})$ durante el periodo analizado. Tres sismos en la ZWB fueron particularmente significativos por su ubicación al oeste del Valle Central y generar intensidades (MM) de hasta $\mathrm{V}$ en una amplia zona del centro de Costa Rica. Esos son los sismos de Naranjo del 6 de marzo de $1992\left(\mathrm{M}_{\mathrm{w}} 6,5\right)$, de Zarcero del 8 de octubre del $2010\left(M_{w}\right.$ 5,9, Barquero \& Rojas, 2011) y de Turrúcares del 13 de mayo del $2011\left(\mathrm{M}_{\mathrm{w}} 6,0\right.$, Barquero et al., 2012).

\section{CONCLUSIONES}

La RSN fue creada en 1982 mediante un convenio entre la Sección de Sismología, Vulcanología y Exploración Geofísica de la ECG de la UCR, que funciona desde 1973 y el Área de Amenazas y Auscultación Sísmica y Volcánica del ICE, que funciona desde 1974. El aporte de la RSN a la investigación en temas relacionados con la Sismología ha sido notorio durante los últimos 30 años. Desde la primera publicación de la RGAC en 1984 y hasta el volumen 50 publicado en el año 2013 los investigadores de la RSN, tanto del ICE como de la UCR, han estado involucrados como autores en 63 publicaciones, lo cual representa el $75 \%$ de los trabajos en el campo de la Sismología y el 13\% de la totalidad de las publicaciones de la RGAC. Los temas aportados por los investigadores de la RSN en la RGAC tratan especialmente la sismotectónica y zonas sísmicas de Costa Rica y la sismicidad reciente e histórica de Costa Rica, incluyendo artículos sobre terremotos específicos. En todas estas investigaciones se han usado sismos registrados por las estaciones de la RSN.

Desde 1976, se emiten comunicados desde la UCR con información de sismos sentidos que se han recopilado en una base de datos que ha sido analizada en este artículo. Está base de datos está constituida por 3363 sismos sentidos durante el periodo comprendido entre el 28 de julio de 1976 y el 31 de diciembre del 2013. La difusión del reporte de sismos sentidos se realiza por varios canales que incluyen una página web desde el 2003 y las redes sociales Facebook y Twitter desde el 2012.

Durante el periodo analizado, la cantidad anual de sismos sentidos reportados por la RSN ha variado entre 15 y 353. Los años con más registros de sismos sentidos fueron 1991, 2012 y 2013, con 353, 264 y 261, sismos, respectivamente. La gran cantidad de sismos sentidos en esos años se debe a la ocurrencia de terremotos, sus réplicas y sismos inducidos. El promedio anual de sismos que fueron percibidos por la población de Costa Rica para el periodo analizado fue de 90. Esto implica que el promedio mensual es de 7,5, el promedio semanal es de 1,9 y que en algún punto de Costa Rica fue reportado sentido un temblor cada 5 días.

El mes del año con más reportes de sismos sentidos ha sido abril con 406 debido a que dos grandes terremotos ocurrieron ese mes: el terremoto de Golfito del 2 de abril de $1983\left(\mathrm{M}_{\mathrm{w}} 7,3\right)$ y el terremoto de Limón del 22 de abril de 1991 $\left(\mathrm{M}_{\mathrm{w}} 7,7\right)$. Con respecto al día del mes, los días 23, 9 y 26 , son los que han presentado más sismos sentidos, con 152, 138 y 136. Estas "anomalías" se correlacionan con las réplicas del día siguiente a los terremotos de Limón de 1991 (día 22), Cinchona en el 2009 (día 8) y Cóbano en 1990 (día 25). La hora local del día con más temblores sentidos durante 1976-2013 es entre las 2:00 y 2:59 a.m., con 168 sismos y luego entre la 1:00 y 1:59 a.m., con 164 sismos. Las horas de la madrugada, entre la 1:00 y 5:59 am se encuentran todas sobre el promedio diario de 140 sismos y esto podría explicarse debido a una mayor percepción de los sismos durante la quietud de la madrugada, cuando la mayoría de las personas se encuentran en reposo. La percepción de la población de la alta sismicidad en Semana Santa proviene de la experiencia vivida por el terremoto de Golfito. Con excepción de 1983, la Semana Santa del resto de años no representa una "anomalía" en la cantidad de sismos sentidos.

Con respecto a la magnitud, la mayoría de los sismos sentidos (47\%) han tenido magnitudes de entre 3,0 y 3,9. Durante el periodo analizado, 205 sismos sentidos han tenido una magnitud de entre 5,0 y 5,9 y 23 sismos han tenido una magnitud de 
entre 6,0 y 6,9. Estos números implican que en Costa Rica durante el periodo analizado se han sentido en promedio 5 sismos de magnitud de entre 5,0 y 5,9 por año y un sismo de magnitud de entre 6,0 y 6,9 cada dos años. Cinco terremotos han sobrepasado la magnitud de 7,0 , estos son los terremotos de Golfito en 1983, Cóbano en 1990 (2 sismos), Limón en 1991 y Sámara en el 2012. Desde 1821, año en que Costa Rica adquiere su independencia, el país ha sufrido 67 sismos destructivos, de los cuales 14 han tenido magnitudes mayores a 7,0. Esto implica un promedio de un sismo destructivo cada 3 años y un terremoto de magnitud mayor a 7,0 cada 14 años. Con respecto a la profundidad, la mayoría $(83,7 \%)$ de los sismos sentidos fueron superficiales, con hipocentros menores a $30 \mathrm{~km}$.

La alta sismicidad de Costa Rica se debe a su localización en una zona de subducción y cerca del punto triple entre las placas del Coco, Caribe y Nazca. Durante 1976-2013, 87 sismos con magnitud mayor a 5,5 ocurrieron en Costa Rica y representan el 98.2\% (i.e., 5,72 x $1016 \mathrm{~J}$ ) del total de la energía liberada por los 3363 sismos que conforman la base de datos de sismos sentidos de la RSN (i.e., 5,83 x 1016 J). El origen de estos puede separarse en seis fuentes sísmicas: subducción (procesos superficiales), fallamiento en la zona al norte de la ZFP, fallamiento en el CDCCR y FAV, fallamiento relacionado con el CDNP, fallamiento en el interior de las placas Caribe y del Coco y deformación interna de la placa del Coco en la ZWB. Las fuentes sismogeneradoras con mayor liberación de energía durante el periodo de observación fueron los procesos superficiales de la subducción de la placa del Coco $(54,5 \%$ del total de la energía liberada), en donde ocurrieron los terremotos de Golfito, Cóbano y Sámara, y el CDNP (38,7 \%) en donde ocurrió el terremoto de Limón que representa el $38,4 \%$ del total de la energía liberada por todos los sismos del periodo estudiado. Con respecto a la frecuencia de sismos de magnitudes mayores a 5,5 , los procesos superficiales de subducción generaron 41 sismos, seguidos por el fallamiento al norte de la ZFP con 21 y los sismos ocurridos en el CDCCR y FAV con 11. Ocho eventos ocu- rrieron en la ZWB por deformación de la placa del Coco a profundidad intermedia y únicamente dos sismos ocurrieron por deformación interna de las placas del Coco y la placa Caribe a más de $150 \mathrm{~km}$ de los límites de placas. La ZWB y los sismos por intraplaca representan sólo el 1,0 $\%$ y $0,1 \%$ del total de energía liberada durante el periodo observado.

\section{AGRADECIMIENTOS}

Agradecemos a todo el personal profesional y técnico, incluyendo a las jefaturas y cuerpo administrativo que han colaborado con la RSN a lo largo de más de 30 años tanto en la UCR como en el ICE. A Luis Diego Morales y Walter Montero por promover la RSN a lo largo de su historia. A los siguientes asistentes en la UCR: Juan Luis Porras, Andrea Moya, Nathalie Chavarría, Roberto Masis, Carlos Chamorro, María Fernanda Jiménez, Jhenory Segura, Yendry Vargas y César Montero. También agradecemos

\section{REFERENCIAS BIBLIOGRÁFICAS}

ALVARADO, G.E. \& MORALES, L.D.,1988: Un siglo de estudios sismográficos.- Rev. Geol. Amér. Central, 9: 113-115.

ALVARADO, G.E., MORALES, L.D., MONTERO, W., CLIMENT, A. \& ROJAS, W., 1988: Aspectos sismológicos y morfotectónicos en el extremo occidental de la Cordillera Volcánica Central de Costa Rica.- Rev. Geol. Amér. Central, 9: 75-98.

BARQUERO, R. \& ROJAS, W., 1994: Sismicidad inducida por el terremoto de Limón.-Rev. Geol. Amér. Central, vol. esp. Terremoto de Limón: 111-120.

BARQUERO, R. \& ROJAS, W., 2009: Resumen de la actividad sísmica en Costa Rica durante el año 2007.- Rev. Geol. Amér. Central, 40: 85-90. 
BARQUERO, R. \& ROJAS, W., 2010: Resumen de la actividad sísmica y volcánica en Costa Rica durante el año 2009.- Rev. Geol. Amér. Central, 42: 127-134.

BARQUERO, R. \& ROJAS, W., 2011: Resumen de la actividad sísmica y volcánica en Costa Rica durante el año 2010.- Rev. Geol. Amér. Central, 44: 157-166.

BARQUERO, R., ROJAS, W. \& FERNÁNDEZ, M., 2006: Resumen de la actividad sísmica en Costa Cica durante el año 2006.Rev. Geol. Amér. Central, 34-35: 167171.

BARQUERO, R., ROJAS, W. \& VARGAS, A., 2012: Resumen de la actividad sísmica y volcánica en Costa Rica durante el año 2011.- Rev. Geol. Amér. Central, 46: 189198.

BARQUERO, R., LESAGE, P., METAXIAN, J.P., CREUSOT, A. \& FERNÁNDEZ, M., 1995: La crisis sísmica en el volcán Irazú en 1991 (Costa Rica).- Rev. Geol. Amér. Central, 18: 5-18.

BAUMGARTNER, P. O., FLORES, K., BANDINI, A.N., GIRAULT, F. \& CRUZ, D., 2008: Upper Triassic to Cretaceous radiolaria from Nicaragua and northern Costa Rica - The Mesquito Composite Oceanic Terrane.- Ofioliti, 33:1-19.

BILEK, S. L., SCHWARTZ, S. AND DESHONE, H., 2003. Control of seafloor roughness in earthquake rupture behavior.- Geology, 31 : 455-458.

BOSCHINI, I. M., ALVARADO, G.E. \& ROJAS, W., 1988: El terremoto de Buenavista de Pérez Zeledón (Julio 3, 1983): evidencia de una fuente sismogénica intraplaca desconocida en Costa Rica.- Rev. Geol. Amér. Central, 8: 111-121.
BOSCHINI, I.M. \& MONTERO, W., 1994: Sismicidad histórica e instrumental del Caribe de Costa Rica.- Rev. Geol. Amér. Central, vol. esp. Terremoto de Limón: 6572.

BOSCHINI, I.M. \& MONTERO, W., 1994: Sismicidad histórica e instrumental del Caribe de Costa Rica.- Rev. Geol. Amér. Central, vol. esp. Terremoto de Limón: 65-72.

BOWLAND, C., 1993: Depositional history of the western Colombian Basin, Caribbean Sea, revealed by seismic stratigraphy.- En: Geol. Soc. Am. Bull., 105(10): 1321-1345, DOI: 10.1130/0016-7606(1993)105.

CAMACHO, E., 1991: The Puerto Armuelles earthquake (southwestern Panama) of july 18, 1934.- Rev. Geol. Amér. Central, 13: 1-13.

CAMACHO, E., 1994: El tsunami del 22 de abril de 1991 en Bocas del Toro, Panamá. Rev. Geol. Amér. Central, vol. esp. Terremoto de Limón: 61-64.

CAMACHO, E. \& VÍQUEZ, V., 1993: Historical seismicity of the north Panama deformed belt.- Rev. Geol. Amér. Central, 15: 49-64.

CAMACHO, E. \& VÍQUEZ, V., 1994: Licuefacción y hundimientos costeros en el noroeste de Panamá durante el terremoto de Limón.- Rev. Geol. Amér. Central, vol. esp. Terremoto de Limón: 133-138.

CORREA-MORA, F., DEMETS, C. ALVARADO, D., TURNER, H. L., MATTIOLI, G., HERNANDEZ, D., PULLINGER, D., RODRIGUEZ M. \& TENORIO, C., 2009: GPS-derived coupling estimates for the Central America subduction zone and volcanic arc faults: El Salvador, Honduras and Nicaragua.Geophys. J. Int., 179: 1279-1291. doi: 10.1111/j.1365-246X.2009.04371.x. 
CORRIGAN, J., MANN, P., \& INGLE, J.C., 1990: Forearc response to subduction of the Cocos Ridge, PanamaCosta Rica: Geological Society of America Bulletin, v. 102, p. 628-652, doi:10.1130/0016-7606(1990)102<0628: FRTSOT $>2.3 . \mathrm{CO} ; 2$.

DEMETS, C., 2001: A new estimate for present-day Cocos-Caribbean plate motion: Implications for slip along the Central American volcanic arc.- Geophysical Research Letters, 28 (21): 4043-4046.

DENGO, G., 1985: Mid America: Tectonic setting for the Pacific margin from southern Mexico to northwestern Columbia.- En: NAIRN, E \& STECHLI, F. G. (ed.): The ocean basins and margins.- Plenum Press New York: 123-180.

DENYER, P., ARIAS, O. \& PERSONIUS, S., 1994a: Efecto tectónico del terremoto de Limón.- Rev. Geol. Amér. Central, vol. esp. Terremoto de Limón: 39-52.

DENYER, P., MONTERO, W. \& ALVARADO, G.E., 2003: Atlas tectónico de Costa Rica.81 págs. Ed. Univ. Costa Rica (2da edición); San José.

DENYER, P., PERSONIUS, S. \& ARIAS, O., 1994b: Generalidades sobre los efectos geológicos del terremoto de Limón.- Rev. Geol. Amér. Central, vol. esp. Terremoto de Limón: 29-38.

FAN, G., BECK, S. \& WALLACE, T., 1993: The seismic source parameters of the 1991 Costa Rica aftershock sequence: Evidence for a transcurrent plate boundary.- J. Geophys. Res. 98: 15759-15778.

FERNÁNDEZ, M., 1996: Evaluación del hipotético sistema de falla transcurrente esteoeste de Costa Rica.- Rev. Geol. Amér. Central, 19/20: 57-74.
FERNÁNDEZ, M. \& BARQUERO, R., 2004: Sismicidad de Costa Rica durante el año 2004.- Rev. Geol. Amér. Central, 31: 93 97.

FERNÁNDEZ, M. \& BARQUERO, R., 2005: Sismicidad de Costa Rica durante el año 2005.- Rev. Geol. Amér. Central, 33: 9196.

FERNÁNDEZ, M. \& MONTERO, W., 2002: Fallamiento y sismicidad del área entre Cartago y San José, valle central de Costa Rica.- Rev. Geol. Amér. Central, 26: 25-37.

FERNÁNDEZ, M. \& PACHECO, J., 1998: Sismotectónica de la Región Central de Costa Rica.- Rev. Geol. Amér. Central, 21: 5-23.

FERNÁNDEZ, M., MORA, M. \& BARQUERO, R., 1998: Los procesos sísmicos en el volcán Irazú (Costa Rica).- Rev. Geol. Amér. Central, 21: 47-59.

FERNÁNDEZ, M., PACHECO, J. \& MORALES, T., 1996: Complejidad de la estructura sísmica de la Región Central de Costa Rica, según un análisis multifractal.- Rev. Geol. Amér. Central, 19/20: 29-36.

FRANCO, A., LASSERRE, D., LYONCAEN, H., KOSTOGLODOV, V., MOLINA, E., GUZMAN-SPEZIALE, M., MONTEROSSO, D., ROBLES, V., FIGUEROA, C., AMAYA, W., BARRIER, E., CHIQUIN, L., MORAN, S., FLORES, O., ROMERO, J., SANTIAGO, J. A., MANEA M. \& MANEA V. C., 2012: Fault kinematics in northern Central America and coupling along the subduction interface of the Cocos Plate, from GPS data in Chiapas (Mexico), Guatemala and El Salvador.- Geophys. J. Int., 189: 1223-1236, doi: 10.1111/j.1365246X.2012.05390.x 
FRENCH, S. W., L. M. WARREN, K. M. FISCHER, G. A. ABERS, W. STRAUCH, J. M. PROTTI, \& V. GONZALEZ, 2010: Constraints on upper plate deformation in the Nicaraguan subduction zone from earthquake relocation and directivity analysis.- Geochem. Geophys. Geosyst., 11, Q03S20, DOI:10.1029/2009GC002841.

GOES, S., VELAZCO, A. \& SCHWARTZ S. 1993: The april 22, 1991, Valle de la Estrella, Costa Rica $\left(\mathrm{M}_{\mathrm{w}}\right.$ 7.7) earthquake and its tectonic implications. A broadband study.- J. Geophys. Res., 98:81278142 .

HAUFF, F., K. HOERNLE, P. VAN DEN BOGAARD, G. ALVARADO, \& D. GARBE-SCHÖNBERG, 2000: Age and geochemistry of basaltic complexes in western Costa Rica: Contributions to the geotectonic evolution of Central America.Geochem. Geophys. Geosyst., 1(1):1009, doi:10.1029/1999GC000020.

HUSEN S., KISSLING E. \& QUINTERO, R., 2002: Tomographic evidence for a subducted seamount beneath the Gulf of Nicoya, Costa Rica: The cause of the $1990 \mathrm{M}_{\mathrm{w}}=7.0$ Gulf of Nicoya earthquake.- Geophys. Res. Letters, 29 (8), 1238, 10.1029/2001GL014045.

KOBAYASHI, D., P. LAFEMINA, H. GEIRSSON, E. CHICHACO, A. A. ABREGO, H. MORA, \& E. CAMACHO, 2014: Kinematics of the western Caribbean: Collision of the Cocos Ridge and upper plate deformation.- Geochem. Geophys. Geosyst., 15, DOI:10.1002/ 2014GC005234.

LA FEMINA, P., T. H. DIXON, R. GOVERS, E. NORABUENA, H. TURNER, A. SABALLOS, G. MATTIOLI, M. PROTTI, \& W. STRAUCH, 2009: Fore-arc motion and Cocos Ridge collision in Central America, Geochem.
Geophys. Geosyst., 10, Q05S14, doi:10.1029/2008GC002181.

LINKIMER, L., 2008a: Application of the kriging method to draw isoseismal maps of the significant 2002-2003 Costa Rica earthquakes.Rev. Geol. Amér. Central, 38: 119-134.

LINKIMER, L., 2008b: Relationship between peak ground acceleration and Modified Mercalli intensity in Costa Rica.- Rev. Geol. Amér. Central, 38: 81-94.

LINKIMER, L., ARROYO, I. \& MONTERO, W., 2014: Enjambres sísmicos en la placa Caribe y la microplaca de Panamá disparados por el terremoto de Nicoya $\left(7,6 \mathrm{M}_{\mathrm{w}}\right)$ del 5 de septiembre del 2012.- Rev. en Torno a la Prevención, 12: 23-31.

LINKIMER, L., ARROYO, I., MORA, M.M., VARGAS, A., SOTO, G.J., BARQUERO, R., ROJAS, W., TAYLOR, W. \& TAYLOR, M., 2013: El terremoto de Sámara (Costa Rica) del 5 de setiembre del $2012\left(\mathrm{M}_{\mathrm{w}}\right.$ 7,6).- Rev. Geol. Amér. Central, 49: 73-82.

LINKIMER, L., BARQUERO, R., VARGAS, A., ROJAS, W., TAYLOR, M. \& ARAYA, M.C., 2013: Actividad sísmica en Costa Rica durante el 2012.- Rev. Geol. Amér. Central, 49: 141-148.

LINKIMER, L., S. L. BECK, S. Y. SCHWARTZ, G. ZANDT, \& V. LEVIN, 2010: Nature of crustal terranes and the Moho in northern Costa Rica from receiver function analysis.-Geochem. Geophys. Geosyst., 11: Q01S19, DOI:10.1029/2009GC002795.

LÜCKE \& LINKIMER, 2014: Redes Sociales y Sismología: educación y prevención en torno a amenazas sísmicas.- Reflexiones, 93(2): 23-33.

MACKENZIE, L., G. A. ABERS, K. M. FISCHER, E. M. SYRACUSE, J. 
M. PROTTI, V. GONZALEZ, \& W. STRAUCH, 2008: Crustal structure along the southern Central American volcanic front, Geochem. Geophys. Geosyst., 9, Q08S09, DOI:10.1029/2008GC001991.

MANN, P., ROGERS, R. \& GAHAGAN, L., 2007: Overview of plate tectonic history and its unresolved tectonic problems.- En: BUNDSHUH, J. \& ALVARADO, G. (ed.): Central America: Geology, Resources and Hazards.- Taylor and Francis New York: 201-237.

MARSHALL, J.S., FISHER, D.M., \& GARDNER, T.W., 2000: Central Costa Rica deformed belt: Kinematics of diffuse faulting across the western Panama block.Tectonics, 19: 468-492.

MATUMOTO, T., OHTAKE, M, LATHAM, G. \& UMAÑA, J., 1977: Crustal structure in southern Central America.- Bulletin of Seismological Society of America, 67(1): 121-134.

MONTERO, M., 1986: Periodos de recurrencia y tipos de secuencias sísmicas de los temblores interplaca e intraplaca en la región de Costa Rica.- Rev. Geol. Amér. Central, 5: $35-72$.

MONTERO, W., 1999: El terremoto del 4 de marzo de $1924(\mathrm{Ms}=7,0)$ : ¿Un gran temblor interplaca relacionado al límite incipiente entre la placa del Caribe y la Microplaca de Panamá?.- Rev. Geol. Amér. Central, 22: $25-62$.

MONTERO, W., 2001: Neotectónica de la región central de Costa Rica: frontera oeste de la microplaca de Panamá.- Rev. Geol. Amér. Central, 24: 29-56.

MONTERO, W., 2003: El sistema de falla Atirro-Río Sucio y la cuenca de traccíon de Turrialba-Irazú: identificación tectónica relacionada con la colisión del le- vantamiento del Coco.- Rev. Geol. Amér. Central, 28: 5-29.

MONTERO, W. \& ALVARADO, G., 1995: El terremoto de Patillos del 30 de diciembre de $1952(\mathrm{Ms}=5,9)$ y el contexto neotectónico de la región del volcán Irazú, Costa Rica.Rev. Geol. Amér. Central, 18: 25-42.

MONTERO, W. \& DENYER, P., 2011, Fallamiento neotectónico de la península de Nicoya y su relación con el escape tectónico del antearco centroamericano. -Rev. Geol. Amér. Central, 45: 9-52.

MONTERO,W.\& KRUSE, S., 2006: Neotectónica y geofísica de la falla Agua Caliente en los valles de Coris y del Guarco.- Rev. Geol. Amér. Central, 34/35: 43-58.

MONTERO, W. \& MORALES, L.D., 1990: Deformación y esfuerzos neotectónicos en Costa Rica. .- Rev. Geol. Amér. Central, 11: 69-84.

MONTERO, W. \& ROJAS, W., 2014: Las fallas Purires y Piragres, y su relación con la secuencia sísmica de Puriscal de 1990.- Rev. Geol. Amér. Central, 50: 39-69.

MONTERO, W. ROJAS, W. \& LINKIMER, L., 2013, Neotectónica de las fallas Ochomogo y Capellades y su relación con el sistema de falla Aguacaliente, falda sur macizo Irazú-Turrialba, Costa Rica.- Rev. Geol. Amér. Central, 48: 119-139.

MONTERO, W., BARAHONA, M. ROJAS, W. \& TAYLOR, M., 2005: Los sistemas de falla Agua Caliente y Río Azul y relevos compresivos asociados, Valle Central de Costa Rica.- Rev. Geol. Amér. Central, 33: 7-27.

MONTERO, W., CAMACHO, E., ESPINOZA, A. \& BOSCHINI, I. 1994: Sismicidad y marco neotectónico de Costa Rica y Panamá.- Rev. Geol. Amér. Central, vol. esp. Terremoto de Limón: 73-82. 
MONTERO, W., PARDO, M., PONCE, L., ROJAS, W. Y FERNÁNDEZ, M., 1994b: Evento principal y réplicas importantes del terremoto de Limón.- Rev. Geol. Amér. Central, vol. esp. Terremoto de Limón: 93-102.

MONTERO, W., SOTO, G. J., ALVARADO, G.E. \& ROJAS, W., 2010: División del deslizamiento tectónico y transtensión en el macizo del volcán Poás (Costa Rica), basado en estudios neotectónicos y de sismicidad histórica.- Rev. Geol. Amér. Central, 43: 13-36.

MORA, M.M. \& PERALDO, G., 2011: Análisis macrosísmico del terremoto de Buenavista de Pérez Zeledón, 3 de julio de 1983 $(\mathrm{Ms}=6,1)$, Costa Rica.- Rev. Geol. Amér. Central, 44: 41-70.

MORA, S. \& MORA, R., 1994: Los deslizamientos causados por el terremoto de Limón: factores de control y comparación con otros eventos en Costa Rica.- Rev. Geol. Amér. Central, vol. esp. Terremoto de Limón: 139-152.

MORA, S. \& YASUDA, S., 1994: Licuefacción de suelos y fenómenos asociados durante el terremoto de Limón.- Rev. Geol. Amér. Central, vol. esp. Terremoto de Limón: 121-132.

MORALES, L. D., 1985: Las zonas sísmicas de Costa Rica y alrededores.- Rev. Geol. Amér. Central, 3: 69-101.

MORALES, L. D., 1986: Historia de la Sismología en Costa Rica.- Rev. Fil. Univ. Costa Rica, 24 (59): 93-104.

MORALES, L. D., 1994: Daños causados por el terremoto de Limón: pérdidas de medidas de mitigación.- Rev. Geol. Amér. Central, vol. esp. Terremoto de Limón: 201-210.

MORALES, L. D. \& MONTERO, W., 1984: Los temblores sentidos en Costa Rica durante:
1973-1983, y su relación con la sismicidad del país.- Rev. Geol. Amér. Central, 1: 29-56.

MORELL, K. D., FISHER, D. M., GARDNER, T. W., 2008: Inner forearc response to subduction of the Panama Fracture Zone, southern Central America.- Earth and Planetary Science Letters, 265: 82-95.

MORELL, K. D., FISHER, D. M., GARDNER, T. W., LA FEMINA, P., DAVIDSON, D. \& TELETZKE A., 2011: Quaternary outer fore-arc deformation and uplift inboard of the Panama Triple Junction, Burica Peninsula.- J. Geoph. Res. 116: B05402, DOI:10.1029/2010JB007979.

PACHECO, J. F., QUINTERO, R., VEGA, F., SEGURA, J., JIMÉNEZ, W. \& GONZÁLEZ, W., 2006: The $\mathrm{M}_{\mathrm{w}} 6.4$ Damas, Costa Rica, Earthquake of 20 November 2004: Aftershocks and Slip Distribution. -Bulletin of the Seismological Society of America,. 96 (4A): 1332-1343, doi: $10.1785 / 0120050261$.

PERALDO, G. \& MONTERO, W., 2007: Temblores documentados para el periodo colonial de Costa Rica.- Rev. Geol. Amér. Central, 36: 25-47.

PERALDO, G., MONTERO, W. \& CAMACHO, E., 2006: El terremoto del 29 de mayo de 1879: una ruptura de magnitud Ms 7, en la zona limítrofe de Costa Rica y Panamá.Rev. Geol. Amér. Central, 34/35: 31-42.

PONCE, L., PARDO, M., DOMÍNGUEZ, J., MONTERO, W., ROJAS, W., BOSCHINI, I., SUÁREZ, G. \& CAMACHO, E., 1994: Estudio de réplicas del terremoto de Limón usando datos locales: resultados e implicaciones tectónicas.- Rev. Geol. Amér. Central, vol. esp. Terremoto de Limón: 103-110.

PROTTI, M., GONZÁlEZ, V., NEWMAN, A. V., DIXON, T. H., SCHWARTZ, S. Y., MARSHALL, J. S., FENG, L., WALTER, 
J., MALSERVISI, R. \& OWEN, S. E., 2014: Nicoya earthquake rupture anticipated by geodetic measurement of the locked plate interface.- Nature Geosci. 7: 117-121 (2014). DOI:10.1038/ngeo2038.

RANERO, C. R., A. VILLASEÑOR, J. PHIPPS MORGAN, \& W. WEINREBE, 2005: Relationship between bend-faulting at trenches and intermediate-depth seismicity.- Geochem. Geophys. Geosyst. 6: Q12002, DOI:10.1029/2005GC000997.

RED SISMOLÓGICA NACIONAL, 1985: Una década de registro sismológico continuo en Costa Rica UCR-ICE: 1975-1985.- Rev. Geol. Amér. Central, 3: 173-175.

RED SISMOLÓGICA NACIONAL, 1986: Resumen de la actividad sísmica y volcánica de Costa Rica (Periodo Enero-Agosto 1986).- Rev. Geol. Amér. Central, 5: 105108.

RED SISMOLÓGICA NACIONAL, 1987a: Resumen de la actividad sísmica y volcánica de Costa Rica (Julio-Diciembre 1986).Rev. Geol. Amér. Central, 6: 121-126.

RED SISMOLÓGICA NACIONAL, 1987b: Resumen de la actividad sísmica y volcánica de Costa Rica (Periodo Enero-Julio de 1987).- Rev. Geol. Amér. Central, 7: 187192.

RED SISMOLÓGICA NACIONAL, 1988a: Resumen de la actividad sísmica y volcánica de Costa Rica (Periodo Julio-Diciembre 1987).- Rev. Geol. Amér. Central, 8: 135-139.

RED SISMOLÓGICA NACIONAL, 1988b: Resumen de la actividad sísmica y volcánica de Costa Rica (Periodo EneroJulio 1988).- Rev. Geol. Amér. Central, 9: 107-112.
RED SISMOLÓGICA NACIONAL, 1989: Resumen de la actividad sísmica y volcánica de Costa Rica (Periodo de Julio a Diciembre de 1988).- Rev. Geol. Amér. Central, 10: 101-106.

RED SISMOLÓGICA NACIONAL, 1990: Resumen de la actividad sísmica y volcánica de Costa Rica (Periodo de Enero a Diciembre de 1989).- Rev. Geol. Amér. Central, 11: 99-104.

RED SISMOLÓGICA NACIONAL, 1991: Resumen de la actividad sísmica y volcánica de Costa Rica (Periodo de Enero a Diciembre de 1990).- Rev. Geol. Amér. Central, 12: 103-108.

RED SISMOLÓGICA NACIONAL, 1992: Resumen de la actividad sísmica y volcánica (Periodo de Enero a Diciembre de 1991).- Rev. Geol. Amér. Central, 14: $97-$ 101.

RED SISMOLÓGICA NACIONAL, 1994: Resumen de la actividad sísmica y volcánica (Periodo de Enero a Diciembre de 1993).- Rev. Geol. Amér. Central, 17: 105107.

RED SISMOLÓGICA NACIONAL, 1995: Resumen de la actividad sísmica y volcánica de Costa Rica (Periodo EneroDiciembre 1994).- Rev. Geol. Amér. Central, 18:97-100.

RED SISMOLÓGICA NACIONAL, 1996: Resumen de la actividad sísmica y volcánica (Periodo Enero-Diciembre 1995).- Rev. Geol. Amér. Central, 19/20: 187-191.

RED SISMOLÓGICA NACIONAL, 1998: Resumen de la actividad sísmica y volcánica (Periodo Enero-Diciembre 1996).- Rev. Geol. Amér. Central, 21: 105-109. 
RED SISMOLÓGICA NACIONAL, 2001: Actividad sísmica y volcánica de América Central (Enero 1997-Diciembre 2000).-Rev. Geol. Amér. Central, 25: 107-113.

RED SISMOLÓGICA NACIONAL, 2002: Resumen de la actividad sísmica y volcánica en Costa Rica durante el año 2001.- Rev. Geol. Amér. Central, 26: 101-105.

RED SISMOLÓGICA NACIONAL, 2009: El terremoto de Cinchona del jueves 8 de enero de 2009.- Rev. Geol. Amér. Central, 40: 91-95.

RED SISMOLÓGICA NACIONAL, 2009: Resumen de la actividad sísmica y volcánica en Costa Rica durante el año 2008.- Rev. Geol. Amér. Central, 41: 111-116.

ROJAS, W. \& REDONDO, C., 2002: El temblor de Quepos del 20 de agosto de 1999 (6,9 M w): fuente sísmica y evolución de la sismicidad.Rev. Geol. Amér. Central, 26: 65-70.
ROJAS, W., BUNGUM, H. \& LINDHOLM, C., 1993: Historical and recent earthquakes in Central America.- Rev. Geol. Amér. Central, 16: 5-22.

SUÁREZ, G., PARDO, M., DOMINGUEZ, J., PONCE, L., MONTERO, W., BOSCHINI, I. \& ROJAS, W. 1995: The Limón, Costa Rica earthquake of 22 April, $1991\left(\mathrm{M}_{\mathrm{w}}\right.$ 7.7): evidence of back-arc thrusting and collisional tectonics in a subduction environment.-Tectonics, 14:518-530.

TAYLOR, W., CHAVES, E.J. \& SOTO, G.J., 2012: El sismo de Las Armenias de Upala $\left(5,5 \mathrm{M}_{\mathrm{w}}\right)$, Costa Rica: Una respuesta a la compresión y el movimiento de fluidos en la Cordillera Volcánica de Guanacaste.21 págs. Instituto Costarricense de Electricidad [Inf. interno].

YE, L., LAY, T. \& KANAMORI, H., 2013: Large earthquake rupture process variations on the Middle America megathrust. -Earth and Planetary Sci. Letters, 381: 147-155. 
